\title{
Noise Radiation from Single and Multiple Rod Configurations
}

\author{
Florence V. Hutcheson ${ }^{*}$ and Thomas F. Brooks ${ }^{\dagger}$ \\ NASA Langley Research Center \\ Hampton, Virginia 23681-2199
}

\begin{abstract}
Acoustic measurements were performed on single and multiple rod configurations to study the effect of Reynolds number, surface roughness, freestream turbulence, proximity and wake interference on the radiated noise. The Reynolds number ranged from $3.8 \times 10^{3}$ to $10^{5}$. Directivity measurements were performed to determine how well the dipole assumption for the radiation of vortex shedding noise holds for the different model configurations tested. The dependence of the peak Sound Pressure Level on velocity was also examined. Several concepts for the reduction of the noise radiating from cylindrical rods were tested. It was shown that wire wraps and collar distributions could be used to significantly reduce the noise radiating from rods in tandem configurations.
\end{abstract}

\section{Introduction}

During airport approach, the noise radiating from the aircraft landing gears is a dominant airframe noise source. A number of numerical ${ }^{1-5}$ and experimental studies ${ }^{6-8}$ are being conducted in order to identify and model the noise generation mechanisms at the landing gears. Noise reduction studies ${ }^{9}$ are also under way. Since many components of a landing gear (struts, cables, axles, and wheels) can be modeled by rods of various lengths and cross-sections, characterizing the noise radiating from single and multiple rod configurations is of relevance to the landing gear noise reduction effort.

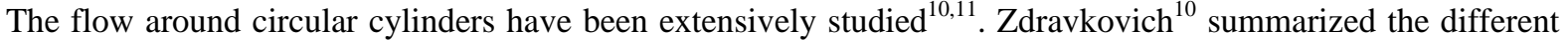
state of flow for smooth cylinders in a uniform flow as laminar, transition-in-wake, subcritical (transition to turbulence in the free shear layer), critical (transition to turbulence in the boundary layer) and fully turbulent. A detailed description of each of these flow regimes is given in reference 10 . The subcritical, critical, and turbulent states of flow are of most interest to the landing gear noise community because of the Reynolds number range it encompasses. For the subcritical and critical states the Reynolds number ranges are $(350-400)<\operatorname{Re}<\left(10^{5}-2 \times 10^{5}\right)$ and $\left(10^{5}-2 \times 10^{5}\right)<\mathrm{Re}$, respectively, where Re is the Reynolds number based on the rod diameter and the freestream velocity of the uniform flow. It is not known at present at which value of Re the fully turbulent state of flow starts. For smooth rods in a uniform flow, Re is expected to be the governing parameter of the state of flow around cylinders. When surface roughness or freestream turbulence are introduced, the structure of the flow may be significantly changed and transitions can occur at lower values of Re.

The noise generated by a cylindrical rod immersed in a uniform or turbulent flow has been well studied. Schlinker et al. performed a very complete examination ${ }^{12,13}$ of vortex shedding noise from single cylindrical rods. They measured far field noise, surface pressure fluctuations and spanwise correlation lengths over a broad range of Reynolds numbers $\left(2 \times 10^{4}\right.$ to $\left.5.5 \times 10^{5}\right)$ and examined the effect of surface roughness on the vortex shedding. They observed that the vortex shedding noise was strong at subcritical Reynolds numbers then decreased sharply in amplitude over a range of supercritical Reynolds numbers. This decrease was followed by a sharp increase in amplitude at postcritical Reynolds numbers. They found the onset of these changes to be influenced by surface roughness. Fujita et al. performed a study ${ }^{14}$ of the Aeolian tones from a single rod at very high Reynolds (namely $2.5 \times 10^{5}$ to $2 \times 10^{6}$ ) and related the decrease and increase of the tone's amplitude in the super- and postcritical regimes to surface pressure fluctuation characteristics. The effect of freestream turbulence on the vortex shedding noise from a single rod has also been studied ${ }^{15,16}$. These experiments revealed the more broadband nature of the vortex shedding noise in the presence of freestream turbulence.

\footnotetext{
* Research Engineer, Aeroacoustics Branch, 2 North Dryden Street, MS/461, AIAA member.

† Senior Research Scientist, Aeroacoustics Branch, 2 North Dryden Street, MS/461, AIAA fellow.
} 
A more limited number of experimental studies have been reported on the aerodynamic sound generated from square rods. Fujita et al. ${ }^{17}$ examined the variation of the Strouhal number, Sound Pressure Levels and surface pressure fluctuations due to the orientation of the bar with respect to the flow. Yoshida et al. ${ }^{18}$ studied the Aeolian tones generated from rectangular bars with rounded corners for different cross section geometries. Both of these studies were conducted for a fixed flow speed (yielding Reynolds number values of $13 \times 10^{3}$ and $41 \times 10^{3}$, respectively, based on the rod geometry). The test models had a smooth surface and were immersed in a uniform flow.

Although numerous studies were performed to examine the flow around rods in tandem or staggered configurations, only a few of the experiments appear to have focused on the aerodynamic sound from rods in such arrangements. These acoustic experiments ${ }^{19,20,21}$ examined, among other things, the effect of rod spacing and diameter on Strouhal numbers and Sound Pressure Levels at Reynolds numbers less than $2.7 \times 10^{4}$. No noise directivity measurements were performed.

In the experimental study reported in the present paper, acoustic measurements were performed on single and multiple rod configurations to study the effect of Reynolds number, surface roughness, freestream turbulence, proximity, and wake interference on the radiated noise. Directivity measurements were performed and several concepts for the reduction of the noise radiating from cylindrical rods were also examined. Although the test matrix included rods of diameter varying from 3/32" to 1" and flow Mach numbers ranging from 0.07 to 0.17 , more extensive measurements were taken on $1 / 2$ " and 1 " rod configurations at the higher $\operatorname{Re}\left(4 \times 10^{4}<\operatorname{Re}<10^{5}\right)$. These configurations are more representative of the flow around the hydraulic lines (or other smaller cylindrical components) of a landing gear.

Presented in this paper is a large portion of the measurements that were acquired, along with an initial analysis of the data. A complete set of the test measurements and further analysis of the data will be presented in a subsequent paper.

\section{Test description}

This acoustic experiment was performed at NASA Langley Research Center in the Quiet Flow Facility (QFF). The QFF is an open jet facility equipped with a 2 by 3 foot rectangular open jet nozzle. The rods were supported above the nozzle by two vertical side plates that are mounted to the short sides of the nozzle (see Fig.1).

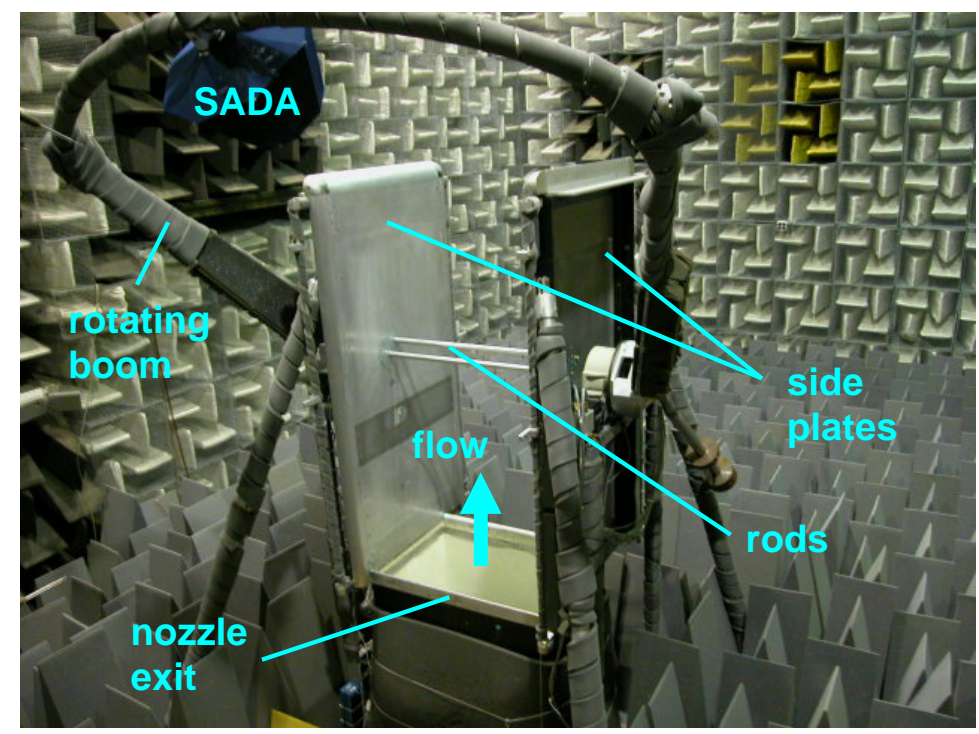

Figure 1. Quiet Flow Facility.

The test models were 3' long aluminum rods of cylindrical or square cross-sections. The diameter of the cylindrical rods ranged from $3 / 32$ ” to 1 ”, while the square rods had a 1 ” by 1 ” cross section. The rods were mounted across the nozzle centerline, 39.5" downstream of the nozzle exit plan. For model configurations that involved two rods, one remained mounted 39.5" downstream of the nozzle exit plan while the other was mounted farther 
downstream (for tandem arrangements) or to the side (for side-by-side arrangements). In this paper, test results are presented for the model configurations that are described in Table 1.

Table 1. Model configurations.

\begin{tabular}{|c|c|}
\hline $\begin{array}{l}\text { Configuration } \\
\text { (sketch of cross-sections) }\end{array}$ & Description \\
\hline & $\begin{array}{l}\text { Single rod - } \\
\text { Diameter : } 3 / 32 ", 1 / 8 ", 1 / 4 ", 1 / 2 ", 1 "\end{array}$ \\
\hline & $\begin{array}{l}\text { Tandem configurations - 1" diameter rods. } \\
\text { Centers 1", 2", 3" or 4.5" apart. }\end{array}$ \\
\hline & $\begin{array}{l}\text { Tandem configuration - 1" diameter rod upstream of a } 1 / 2 \text { " rod. } \\
\text { Centers 3" apart. }\end{array}$ \\
\hline$\rightarrow$ & $\begin{array}{l}\text { Tandem configuration }-1 / 2 \text { " diameter rod upstream of a } 1 \text { " rod. } \\
\text { Centers } 3 \text { " apart. }\end{array}$ \\
\hline & $\begin{array}{l}\text { Side by side configurations - Two 1" diameter rods. Centers } 1.2 \text { ", } \\
\text { 2" or 3" apart. }\end{array}$ \\
\hline & $\begin{array}{l}\text { Square bar (1"x1" cross section). } \\
\alpha=0^{\circ}, 30^{\circ} \text { and } 45^{\circ} \text {. }\end{array}$ \\
\hline$\rightarrow$ & $\begin{array}{l}3 / 4 " \text { diameter rod with } 4 \text { " wide by } 0.2 \text { " thick plate (same span as } \\
\text { rod). No gap between the rod and the plate. }\end{array}$ \\
\hline$\rightarrow$ & $\begin{array}{l}3 / 4 \text { " diameter rod with } 4 \text { " wide by } 0.2 \text { " thick plate. Gap of } 0.1 \text { " } \\
\text { between the rod and the plate. }\end{array}$ \\
\hline Configuration (spanwise view) & Description \\
\hline flo & $\begin{array}{l}\text { Rods with collars - } 1 / 2 \text { " diameter rod; the collars are } 3 / 4 " \text { in } \\
\text { diameter and } 1.5 \text { " long. }\end{array}$ \\
\hline$\leftrightarrow$ & $\begin{array}{l}\text { Rods with wire wrap - } 1 / 2 \text { " diameter rod } \\
\text { Wire diameter: } 1 / 8^{\prime \prime} ; d=2.5^{\prime \prime}\end{array}$ \\
\hline & $\begin{array}{l}\text { Rods with collars - } \\
1 / 2 \text { " diameter rod with collar distribution upstream of a } 1 \text { " diameter } \\
\text { rod. Centers } 3 \text { " apart. }\end{array}$ \\
\hline 4 & $\begin{array}{l}\text { Rods with collars - } \\
1 / 2 \text { " diameter rod with collar distribution downstream of a } 1 \text { " } \\
\text { diameter rod. Centers } 3 \text { " apart. }\end{array}$ \\
\hline$\stackrel{4}{\longrightarrow}$ & $\begin{array}{l}\text { Tandem configuration with wire wrap. Two } 1 \text { " diameter rods; no } \\
\text { gap between the rods; } d=5 \text { ". }\end{array}$ \\
\hline
\end{tabular}


The rod with plate configuration listed in Table 1 models a latch door attached to a landing gear strut. This test model is shown below in Fig.2. The rod is secured to the plate with 17 evenly spaced brackets. The edges of the plate are beveled down to 0.04 " over a distance of 0.27 ". The brackets were used with or without spacers to mount the rod to the plate.

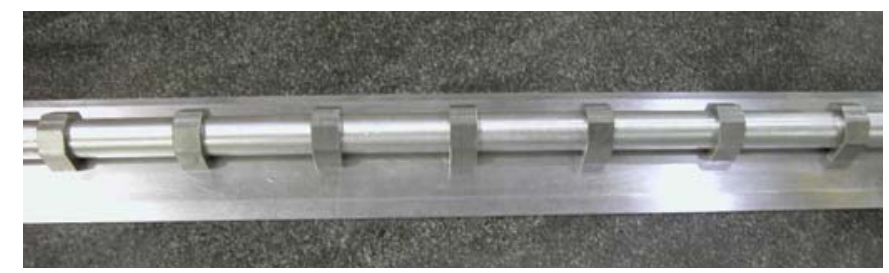

Figure 2. Rod with side plate.

The effect that collar distributions and wire wraps have on the noise radiated by a cylindrical rod or by rods in tandem configurations was examined. These collars and wire wraps were inspired by an experiment conducted by Krish Ahuja et al. ${ }^{21}$ to reduce the noise radiating from car antennas. In that experiment, protrusions in the form of Orings and beads were distributed along the span of a conical rod immersed in a uniform flow. It was shown that the protrusions reduced the radiated noise by rendering the vortex shedding along the span of the rod less coherent. It is also mentioned in reference 21 that similar results can be achieved by wrapping a wire along the span of the rod.

The collars, in the present experiment, had rounded edges and were uniformly distributed along the span of the rod (see Fig.3a). The spacing between collars was varied. For the rod with wire wrap (Fig.3b), a 1/8” copper wire is wrapped along the entire span of the rod.

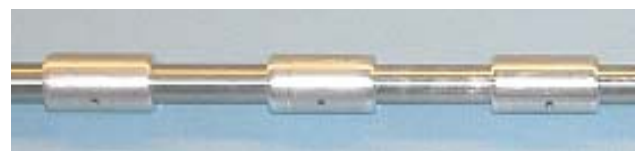

a) 1/2" rod with collar distribution.

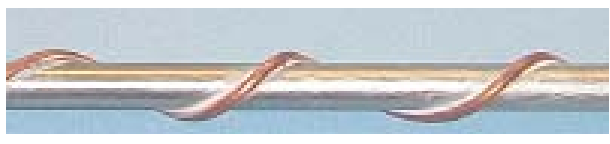

b) 1/2" rod with wire wrap.

Figure 3. Noise reduction devices.

Noise measurements were taken at flow Mach numbers ranging from 0.07 to 0.17 . The models were tested tripped and un-tripped. Grit (\#90 grit; $170 \mu \mathrm{m}$ for average particle size) was applied to the surface of the models for the tripped configurations.

For some of the rod configurations tested, a grid was mounted across the exit plane of the nozzle (as shown in Fig.4). The purpose of the grid was to generate turbulence upstream of the rods for study of rod configurations in freestream turbulent flow. Acoustic foam treatment was glued along each bar of the turbulence grid to attenuate noise from the air flowing through the grid. In this experiment, the rods were mounted 39.5” downstream of the nozzle exit plan, in a region of the flow where the generated turbulence is assumed to be homogeneous.

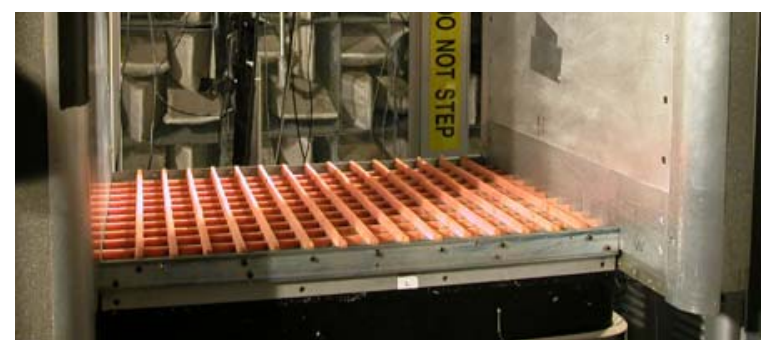

Figure 4. Nozzle grid.

Two different turbulence grids were used. The first one (referred as grid A in the rest of the paper) was designed to generate macro-scales (integral scale) ranging between 0.5 " to 0.92 " and micro-scales (dissipation scale) ranging between 0.07 " to 0.12 ". The grid bars were 0.5 " $\mathrm{x} 0.5$ " in cross section, and the spacing (center to center) between consecutive bars was 2.22". The second grid (grid B) was designed to generate macro-scales in the 0.8"-1.2" range 
and micro-scales in the 0.07 "- 0.12 " range. The bars were 0.8 " 0.8 " in cross section. The spacing (center to center) between consecutive bars was 3.55". The turbulence intensity measured 40 " downstream of the nozzle grid (i.e., near the location of the test models) is approximately $6.5 \%$ for grid $\mathrm{A}$ and $8.5 \%$ for grid B. When a turbulence grid was placed in the nozzle exit plane, measurements were only taken at a flow Mach number of 0.13. (This was the maximum flow speed that could be reached with the nozzle grids in place.)

A sketch of the acoustic test setup is shown in Fig.5. Six microphones were positioned on opposite sides of the test section. These microphones were directed at a point located along the nozzle centerline, 39.5" above the nozzle exit plan (center of the test model at mid-span for single rod configurations). These six microphones were positioned 6.5' away from that center point and at, respectively, $\phi=60^{\circ}, 90^{\circ}, 120^{\circ},-60^{\circ},-90^{\circ}$ and $-120^{\circ}$ elevation. For some of the rod configurations tested, a Small Aperture Directional Array (SADA) was used to make noise measurements at intermediate elevation angles (namely, $\phi=45^{\circ}, 75^{\circ}, 105^{\circ}, 135^{\circ},-45^{\circ},-75^{\circ},-105^{\circ}$ and $-135^{\circ}$ ). In this experiment, the frequency range of interest is between $80 \mathrm{~Hz}$ and $4.8 \mathrm{kHz}$. In this low frequency range the beamwidth of the SADA is very large ${ }^{22}$. As a result, the output of the SADA is equivalent to that obtained from a single microphone. Therefore, in these experiments, the microphone array was used only as practical way to obtain noise measurements at additional elevation angles; the noise spectra at these elevations angles were obtained using a single microphone of the SADA.

Two transient data recorders (NEFF) controlled by a workstation were used to acquire the data at a sampling rate of $142.857 \mathrm{kHz}$. High pass and low pass filters, set respectively at $70 \mathrm{~Hz}$ and $50 \mathrm{kHz}$, were used to condition the outputs from each microphone channel. The noise spectra were obtained by partitioning each time signal into 1000 non-overlapping segments of $2^{13}$ samples, and each time history segment was Fourier transformed using a Hamming window for signal conditioning. The resulting frequency resolution was $17.42 \mathrm{~Hz}$. The background noise pressure field (measured for each of the flow Mach numbers tested, with air flowing through the empty test section) was subtracted (on a $\mathrm{p}^{2}$ basis) from the noise pressure field measurements obtained from the different test model configurations.

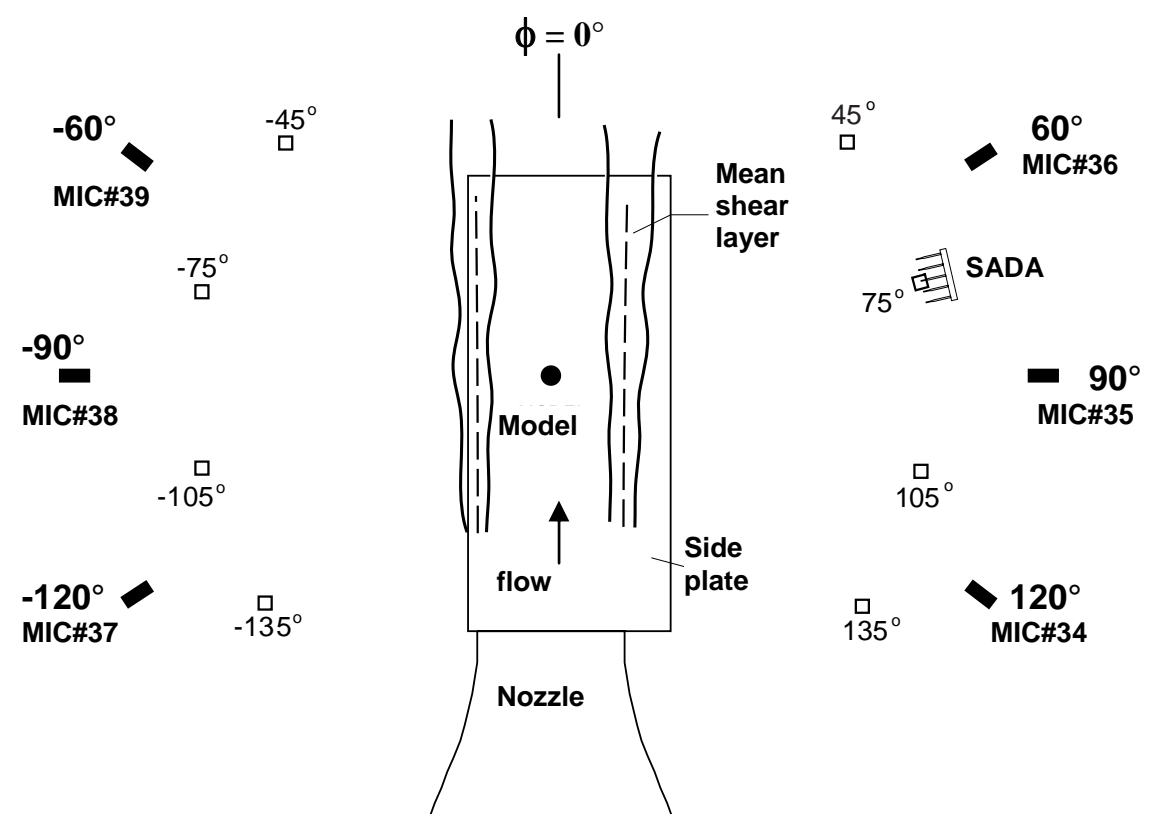

Figure 5. Acoustic test set up.

\section{A. Flow Regimes}

\section{Background and Theory}

The different model configurations examined in the present experiment involved rods of diameter 3/32", 1/8", $1 / 4 ", 1 / 2$ ", and 1". These configurations were tested with a freestream flow Mach number, $\mathrm{M}$, ranging from 0.07 to 0.17. This corresponds to a Reynolds number, Re, varying from $R e=3,879$ (for the $3 / 32$ ” rod at $M=0.07$ ) to $\operatorname{Re}=100,507$ (for the 1" rod at $M=0.17$ ). For a uniform freestream flow and smooth rods, this Reynolds number 
range falls mostly within the subcritical state of flow where transition from laminar to turbulent flow occurs along the free shear layers while the boundary layers remain laminar. There are three sub-regimes within the subcritical state of flow. Zdravkovich ${ }^{10}$ categorized them, as TrSL1 ((350-400) $\left.\leq \operatorname{Re} \leq\left(10^{3}-2 \times 10^{3}\right)\right)$, TrSL2 $\left(\left(10^{3}\right.\right.$ $\left.\left.2 \times 10^{3}\right) \leq \operatorname{Re} \leq\left(2 \times 10^{4}-4 \times 10^{4}\right)\right)$ and TsSL3 $\left(\left(2 \times 10^{4}-4 \times 10^{4}\right) \leq \operatorname{Re} \leq\left(10^{5}-2 \times 10^{5}\right)\right)$. In TrSL1, transition waves appear as undulations of the free shear layers. In TrSL2, the transition waves roll up into discrete eddies along the free shear layer. In TrSL3, the transition to turbulence occurs in the free shear layer near the side of the cylinder and the formation of alternating eddies takes place close to the rear of the cylinder. TrSL2 is associated with a rise of the RMS fluctuating lift coefficient $C_{L}$ from approximately a value of 0.05 to a value of 0.6 . During the TrSL3 regime, $\mathrm{C}_{\mathrm{L}}$ remains approximately constant near a value of 0.6.

The application of grit to the surface of the rods or the presence of freestream turbulence is likely to trigger the onset of the critical state of flow in which transition to turbulence occurs in the boundary layer. As reported in reference 10, the critical state can be subdivided into 5 sub-regimes: (i) a precritical regime, (ii) a one-bubble regime, (iii) a two-bubble regime, (iv) a supercritical regime, (v) a post-critical regime. The precritical regime Reynolds number range is from $\left(\left(10^{5}-2 \times 10^{5}\right) \leq \operatorname{Re} \leq\left(3 \times 10^{5}-3.4 \times 10^{5}\right)\right)$. This regime contains the onset of transition in the free shear layer along the separation lines and is associated with fall in $C_{L}$ from a value near 0.6 to a value of approximately 0.25 . The one-bubble regime Reynolds number range is from $\left(\left(3 \times 10^{5}-3.4 \times 10^{5}\right) \leq \operatorname{Re} \leq\left(3.8 \times 10^{5}-4 \times 10^{5}\right)\right)$. The two-bubble regime Reynolds number range is from $\left(\left(3.8 \times 10^{5}-4 \times 10^{5}\right) \leq \operatorname{Re} \leq\left(5 \times 10^{5}-10^{6}\right)\right)$. In these two "bubble" regimes, the free shear layer reattaches onto the cylinder surface forming a closed separation bubble region. In the one-bubble regime, the separation bubble only forms on one side of the cylinder. In the two-bubble regime, the separation bubble forms on both sides. Both bubble regimes are associated with a jump in the shedding frequency and are very sensitive to disturbances such as surface roughness and freestream turbulence. In the presence of disturbances, the bubble regimes often do not occur. These two regimes are also characterized by a further decrease in $\mathrm{C}_{\mathrm{L}}$ from a value of approximately 0.25 to a value of 0.05 . The supercritical regime Reynolds number range is from $\left(\left(5 \times 10^{5}-10^{6}\right) \leq \operatorname{Re} \leq\left(3.4 \times 10^{6}-6 \times 10^{6}\right)\right)$ and is associated with the occurrence of transition in the primary laminar separation line in an irregular manner which prevents or weakens periodic vortex shedding. In this regime, $\mathrm{C}_{\mathrm{L}}$ remains approximately constant at a value of 0.05 . Finally, the post-critical regime Reynolds number ranges from $\left(\left(3.4 \times 10^{6}-6 \times 10^{6}\right) \leq \operatorname{Re} \leq(\right.$ unknown) and the boundary layers are fully turbulent before the separation lines. This regime is associated with a return of periodic vortex shedding and a slow rise of $\mathrm{C}_{\mathrm{L}}$ to about a value of 0.25 .

The variation of the RMS fluctuating lift coefficient $C_{L}$ during the subcrital and critical states is summarized in Fig.6.

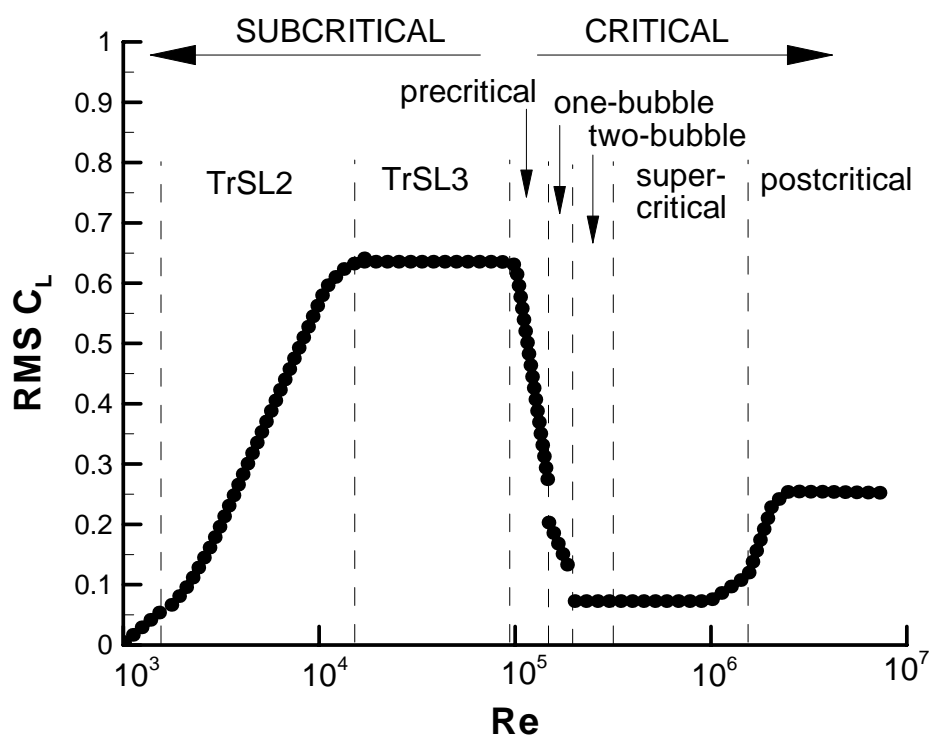

Figure 6. Approximate variation of RMS lift coefficient with Reynolds number for smooth cylinders in uniform flow (data extracted from Fig. 1.11 of reference 10).

Based on the above information, when immersed in a uniform flow of Mach number ranging from 0.07 to 0.17, smooth $1 / 4$ ", $1 / 8^{\prime \prime}$ and $3 / 32$ " diameter rods $\left(3.8 \times 10^{3} \leq \mathrm{Re} \leq 2.5 \times 10^{4}\right)$ are expected to lead to the TrSL2 or TrSL3 
regimes, while smooth 1 " and $1 / 2$ " diameter rods $\left(2 \times 10^{4}<\mathrm{Re}<10^{5}\right)$ are expected to lead to the TrSL3 or the precritical regimes.

\section{B. Predictions}

In the range of Reynolds number over which periodic vortex shedding takes place, the noise is tone-like and radiates like a dipole. The following model has been developed and most commonly used ${ }^{12,14}$ to predict the mean square acoustic pressure of the noise field

$$
p^{2}(r)=\frac{\rho^{2} c^{4} M^{6} L D L_{c} S_{t}^{2} C_{L}^{2}}{16 r^{2}} \cos ^{2} \phi .
$$

In Eq.(1), $\rho$ if the air density, $\mathrm{C}$ is the speed of sound, $M$ is the flow Mach number, $L$ is the rod span, $D$ is the rod diameter, $L_{c}$ is the spanwise correlation length of the surface pressure fluctuation normalized by $D, r$ is the distance from the rod to the observer and $\phi$ is the angle between the freestream and the observer (also referred in this study as the elevation angle). Note that in the supercritical regime in which coherent vortex shedding is weak, the dipole concept no longer describes the acoustic radiation accurately ${ }^{12,14}$.

The directivity function, $\mathrm{D}_{\mathrm{r}}(\phi)$, for the radiated noise can be modeled as that for a translating dipole ${ }^{23}$.

$$
D_{r}(\phi)=\frac{\sin ^{2} \phi_{r}}{\left(1+M \cos \phi_{r}\right)^{4}},
$$

where $\phi_{\mathrm{r}}$ is expressed in the retarded coordinates system ${ }^{22}$.

Equations (1) and (2) will be used to scale some of the results presented in the next sections to study the dependence of the vortex shedding noise Sound Pressure Level (SPL) with respect to known parameters and to determine how well these equations model the radiation of the vortex shedding noise for the different configurations tested.

\section{Experimental Results}

The variation of peak SPL and Strouhal number (St) with respect to Reynolds number or flow Mach number are presented. The results shown were obtained from measurements acquired with microphone 38 (see Fig.5), i.e., for an observer located at a $90^{\circ}$ elevation angle. In these figures, the Strouhal number is calculated as function of the rod diameter, the flow speed, and the frequency of the tone dominating the noise spectra. The frequency value used to calculate St was weighted with respect to the spectral shape of the tone (over a frequency range where lower and upper frequency limits correspond to SPL levels that are $10 \mathrm{~dB}$ down from the peak SPL value). Thus, in the case of a very sharp spectral peak, the weighted frequency will not differ from the peak SPL frequency. But in the case of a tone which SPL, for example, rises to the peak value over a short frequency range and drops back down over a longer frequency range, the weighted frequency will be slightly higher than the peak SPL frequency.

In the rest of this paper, "peak SPL $10 \mathrm{~dB}$ " corresponds to the peak SPL value of the dominant tone in the noise spectra, integrated on a $\mathrm{p}^{2}$ basis over the frequency range which lower and upper limits corresponds to SPL levels that are $10 \mathrm{~dB}$ down from the peak SPL value.

Finally, the directivity results presented are that of the dominant tone in the noise spectra. These directivity measurements were obtained from microphones 37, 38 and 39 at elevation angles $\phi$ of $120^{\circ}, 90^{\circ}$ and $60^{\circ}$, respectively. Directivity measurements obtained with the SADA at intermediate elevation angles are not included in this paper.

\section{A. Single cylindrical rods configurations}

Acoustic measurements were first performed on simple single rod configurations to determine (when possible) the effects of Re, freestream turbulence, and surface grit on the state of the flow around the rod, and on the St value and the peak SPL of the vortex shedding noise. This analysis will aid in the interpretation of the results that are obtained when these rods are used in more complex arrangements in other part of the experiment. For these single rod cases, acoustic measurements were acquired for 1 ”, 1/2", 1/4", 1/8” and 3/32" diameter rods at the following flow Mach number values $0.07,0.09,0.11,0.13,0.15$ and 0.17 . The freestream flow was uniform, and the surface of the rods was either smooth or gritted. Additional measurements were taken at flow a Mach number of 0.13 with grid A or grid B mounted in the exit plan of the nozzle to generate freestream turbulence.

The noise spectra obtained from microphone 38, for each of the above rods and flow speeds consist of a large tone at the rods vortex shedding frequency, and two smaller tones (about $25 \mathrm{~dB}$ lower in level than the dominant 
tone) at twice and three times the vortex shedding frequency. These three tones are observed to broaden (as they drift to higher frequencies) with increasing speeds and decreasing rod diameters. The frequency location and spectral shape of the dominant tone, with and without the nozzle grids and for a flow Mach number of 0.13 are shown in Fig.7a and 7b for the gritted and smooth rods, respectively. It is seen in these figures that the application of grit to the rods leads to a slight shift (of about $100 \mathrm{~Hz}$ at $\mathrm{M}=0.13$ ) to higher frequencies for the 1"and $1 / 2$ " rods vortex shedding tone. This is also true for the $1 / 4$ " rod (spectra not shown) for a flow Mach number greater than 0.11 . The grit leads to a small shift $(40 \mathrm{~Hz})$ to a lower frequency for the $1 / 8$ ” diameter rod and a large shift of about $800 \mathrm{~Hz}$ to a lower frequency for the $3 / 32$ " rod. The shifts to higher vortex shedding frequencies translate into increased St values, while the shifts to lower frequencies lead to lower St values. The variation of St with the flow Mach number for these single rod configurations is shown in Fig.8. It is seen in this figure that for the 1" rod, the application of grit lead to a slightly higher vortex shedding frequency over the entire range of flow Mach numbers tested $\left(4.1 \times 10^{4} \leq \operatorname{Re} \leq 10^{5}\right)$. For the $1 / 2$ " rod, the application of grit increased vortex shedding frequency for flow Mach numbers greater than $.07\left(2 \times 10^{4}<\mathrm{Re}\right)$. For the $1 / 4$ " and 1/8" rods, the presence of the grit raises the vortex shedding frequency for flow Mach numbers greater than 0.11 (i.e.,1.6x $\left.10^{4}<\mathrm{Re}\right)$ and $0.15\left(8 \times 10^{3}<\mathrm{Re}\right)$, respectively. For the rod of 3/32" diameter, the vortex shedding frequency shifted to significantly lower values for all of the flow Mach number tested.

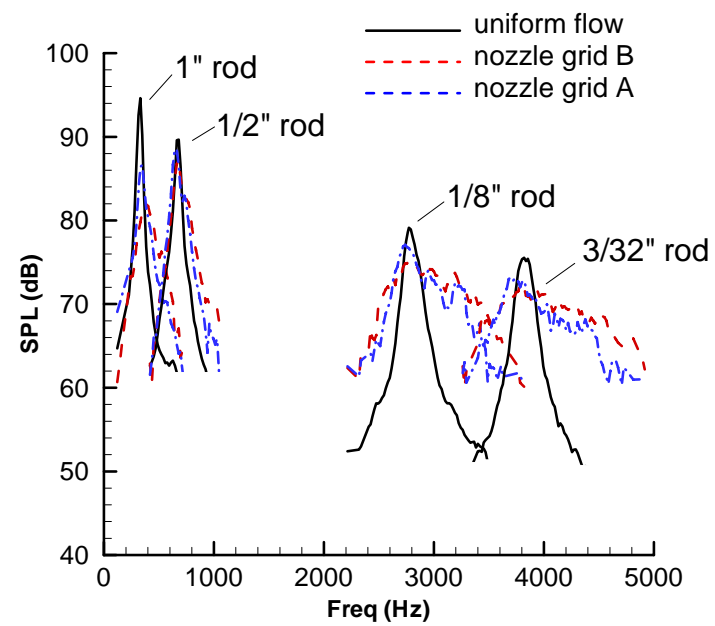

a) Smooth rods

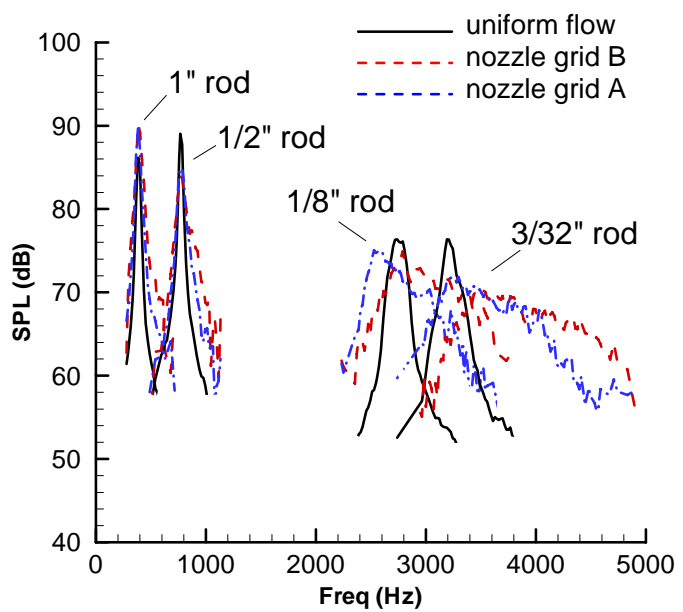

b) Gritted rods

Figure 7. Spectral shape of vortex shedding tone for single rods, with and without freestream turbulence.

For the 1 ”, $1 / 2$ ", $1 / 4$ ", 1/8” and 3/32" diameter rods, the application of grit corresponds to a relative roughness $\mathrm{K} / \mathrm{D}$ of, respectively, $0.66 \%, 1.2 \%, 2.6 \%, 5.3 \%$ and $7.1 \%$. $\mathrm{K}$ is the average size of the grit and is equal to170 microns. For the 3/32" rod, this relative roughness is very large. The shift of the vortex shedding frequency to lower values can be attributed in part by the relative increase in diameter of the rod (due to the presence of the grit), and to a probably larger wake caused by the turbulence generated from these (proportionally speaking) large protrusions which causes the rod profile to approach that of a bluff body. For the 1" and 1/2" rods, PIV measurements ${ }^{24}$ performed at $\mathrm{M}=0.13$ and 0.17 in a previous experiment, show a slight narrowing of the wake when the rods are gritted instead of smooth. This is consistent with the increased vortex shedding frequency and St value observed for the rods at these speeds.

It is also seen in Fig.8 that for the smooth rod configurations, St slightly increases in value with decreasing rod

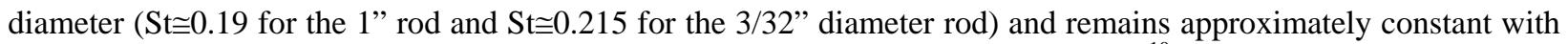
increased M. The latter is consistent with the TrSL2, TrSL3, and precritical regimes ${ }^{10}$. The slight rise of St for the smooth 1" rod for M>0.15 is also consistent with the variation of St observed in previous studies ${ }^{25}$ at the end of the precritical regime. Similarly, for the gritted 1" and 1/2" rods, the initial jump of St (at the lower flow speeds), followed by a small decrease of St to an approximately constant value (at higher flow speeds) is also consistent with the state of flow transitioning from the TrSL3 or precritical regimes, directly to the postcritical regime ${ }^{26}$. A similar variation of St is seen for the gritted 1/4" rod for M>0.11. 
The variation of the peak $\mathrm{SPL}_{10 \mathrm{~dB}}$ of the noise radiating from these single cylindrical rod configurations is shown in Fig.9. In this figure, the SPL levels are scaled with respect to $\left(\mathrm{M}^{6} \mathrm{LD} / \mathrm{r}^{2}\right)$, based on Eq.(1). It is seen that the smooth 1 ", $1 / 2$ " and $1 / 4$ " rods follow the $6^{\text {th }}$ power velocity dependence best. It is also seen that for the smooth 1 ", $1 / 2$ " and 1/4" rods, peak SPL ${ }_{10 \mathrm{~dB}}$ collapses within $2.5 \mathrm{~dB}$. For the smooth 1/8" and 3/32" rods, the collapse of peak $\mathrm{SPL}_{10 \mathrm{~dB}}$ (with the rest of the smooth rod data) is very good at $\mathrm{M}=0.17$ but deteriorates at the lower speeds. At the lowest speed, peak SPL ${ }_{10 \mathrm{~dB}}$ for the 1", 1/2" and 1/4" smooth rods collapse within $1 \mathrm{~dB}$ while the peak SPL $\mathrm{L}_{10 \mathrm{~dB}}$ for the smooth $1 / 8$ " and 3/32" rods are, respectively, $5 \mathrm{~dB}$ and $8 \mathrm{~dB}$ lower than that for the bigger rods. This poor collapse of the peak SPL $10 \mathrm{~dB}$ for the smooth $1 / 8$ " and 3/32" rods at the lower speeds can be attributed to the very low $\mathrm{C}_{\mathrm{L}}$ values associated with the first part of TrSL2 flow regime (see Fig.7(a)). At M=0.07, Re=.5x10 for the $1 / 8$ " rod and $\mathrm{Re}=.38 \times 10^{3}$ for the $3 / 32$ " rod. Based on Fig.7, $\mathrm{C}_{\mathrm{L}}$ is approximately equal to 0.2 at these Reynolds numbers. Assuming a $C_{L}$ value of 0.2 for the $1 / 8$ " and $3 / 32$ " rods at $M=0.07$ and a value of 0.6 for the 1 ”, $1 / 2$ " and $1 / 4$ " rods, scaling with respect to $\mathrm{C}_{\mathrm{L}}{ }^{2}$ would collapse the data within $1 \mathrm{~dB}$. Similarly, the relatively poor collapse of the peak $\mathrm{SPL}_{10 \mathrm{~dB}}$ data for the gritted 1" and 1/2" rod with the rest of the data can be attributed to low $\mathrm{C}_{\mathrm{L}}$ values associated with the postcritical flow regime.

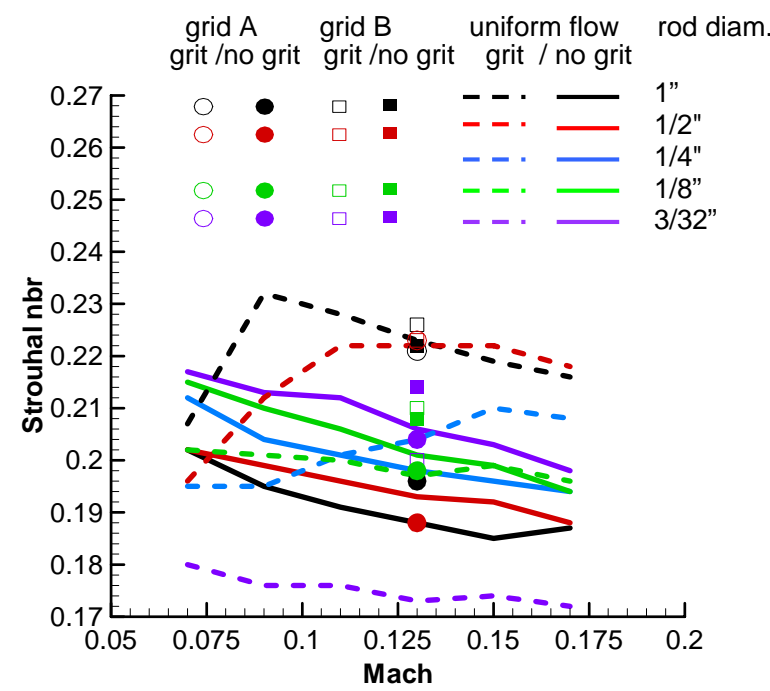

Figure 8. Variation of St with $M$ for single rod configurations.

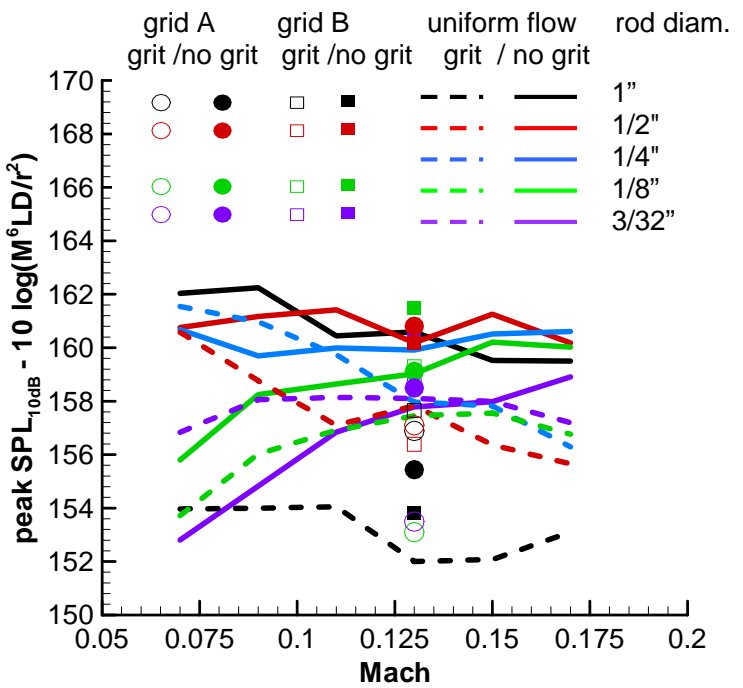

Figure 9. Variation of peak $\mathrm{SPL}_{10 \mathrm{~dB}}$ with $\mathrm{M}$ for single rod configurations.

Regarding the effect of freestream turbulence on the radiated noise, it is observed from Fig.7a and 7b, that the freestream turbulence broadens the spectral tone associated with the vortex shedding of the gritted and smooth rods. This is especially true for the smaller diameter rods, namely the 1/8" and 3/32" rods, for which the "tone" becomes more broadband in nature. It is also observed that the freestream turbulence generated by grid B leads to more broadening of the spectral tone than the turbulence generated by grid A.

The scale of the turbulence, Ts, (integral scale) is expected to range from 0.5 ” to 0.92 ” for grid A and from 0.8 ” to 1.2" for grid B. Thus, the scales of the turbulence generated by both nozzle grids are expected to be larger than the diameters of the rod tested, with the exception of the 1 " rod. For the 1/2" rod, some eddies generated by grid A may be close in size to its diameter.

It is seen in Fig.8 that except in the case of a smooth 1" rod with freestream turbulence from grid B, the freestream turbulence only caused small variations of the St values compare to the uniform flow case. The variation of St observed for the 1/8" and 3/32" diameter rods is suspected to be partly, if not all, due to the broadband nature of the spectral "tone". This broadening of the spectral tone makes the determination of the vortex shedding frequency a little more difficult. In the case of the smooth 1" rod with freestream turbulence from grid B, the value of St increased to that for the gritted 1" rod in a uniform flow. With grid A, St did also increase, but not as much as with grid B. It is also seen in Fig. 7a and 9 that the turbulence (from both grids) causes the peak SPL of the vortex shedding tone to decrease for the 1" rod. For the 1/2" rod, the peak SPL and vortex shedding frequency are mostly unchanged by the presence of freestream turbulence from either grid. In the case of the 1/2" rod, the turbulence 
scales are probably too large with respect to the diameter of the rod to affect its TrSL3 state of flow. It has been reported ${ }^{10}$ that in the TrSL3 state of flow, Ts has to be less than the rod diameter to be effective in promoting and advancing transition toward the separation line and trigger the critical state of flow. Finally, St and peak SPL $10 \mathrm{~dB}$ values are seen to be mostly unchanged by the presence of the freestream turbulence for the gritted 1/2" rod. For the gritted 1" rod, St also remains near the same value with or without the freestream turbulence, but peak SPL $\mathrm{L}_{10 \mathrm{~dB}}$ is increased compare to the uniform flow case.

The above analysis helped define the effect of grit and freestream turbulence on St, peak SPL $10 \mathrm{~dB}$ and the state of flow for most of the single rod configurations tested. The model configurations that will be discussed in the rest of this paper involve rods of diameter ranging from 0.5 " to 1 ". The states of flow which are most consistent with the results discussed above are listed in Table 2 for the $1 / 2$ " and 1 " rod.

Table 2.

\begin{tabular}{|l|l|l|l|l|}
\hline D & $\begin{array}{l}\text { Smooth rod } \\
\text { Uniform flow }\end{array}$ & $\begin{array}{l}\text { Gritted rod } \\
\text { Uniform flow }\end{array}$ & $\begin{array}{l}\text { Smooth rod, } \mathrm{M}=0.13 \\
\text { Freestream turbulence }\end{array}$ & $\begin{array}{l}\text { Gritted rod, } \mathrm{M}=0.13 \\
\text { Freestream turbulence }\end{array}$ \\
\hline $1 "$ & $\begin{array}{l}\text { TrSL3, } 0.07 \leq \mathrm{M} \leq 0.15 \\
\text { maybe precritical at } \mathrm{M}=0.17\end{array}$ & Postcritical & --- & Postcritical \\
\hline $1 / 2^{\prime \prime}$ & TrSL3 & Postcritical & TrSL3 & Postcritical \\
\hline
\end{tabular}

Directivity

The directivity measurements obtained from microphones 37, 38 and 39 are presented in Fig. 10, 11 and 12. In Fig. 10, the measurements are shown for the smooth and gritted 1" rods at all speeds. The data is scaled using Eq.(2) while referenced to the output from microphone 38. It is seen that the data collapse within $1 \mathrm{~dB}$ with the exception of the data acquired for the smooth rod at $\mathrm{M}=0.11$ and for the gritted rod at $\mathrm{M}=0.09$. In these 2 cases, the data scaled within $2 \mathrm{~dB}$. Directivity measurements obtained for the different diameter rods at $\mathrm{M}=0.13$ are displayed in Fig 11 (uniform flow configuration) and in Fig.12 (freestream turbulence configuration). The measurements are plotted against $\mathrm{D}_{\mathrm{r}}(\phi)$. It is seen that for all but one configuration, the data collapse within $1 \mathrm{~dB}$ along the theoretical directivity pattern. For the case of the smooth 1/8" rod with freestream turbulence from grid A., the measurements obtained at an elevation of $60^{\circ}$ depart by $2 \mathrm{~dB}$ from the theoretical value given by Eq. (2). Good agreements with the theoretical directivity pattern were also obtained at the other flow speeds.

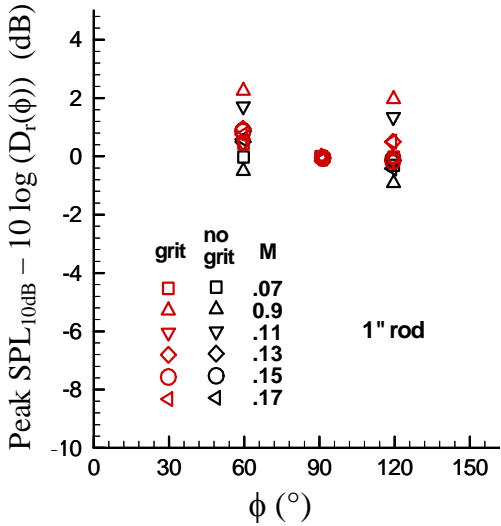

Figure 10. Directivity of vortex shedding tone for a 1 " rod in a uniform flow. Data referenced to microphone 38.

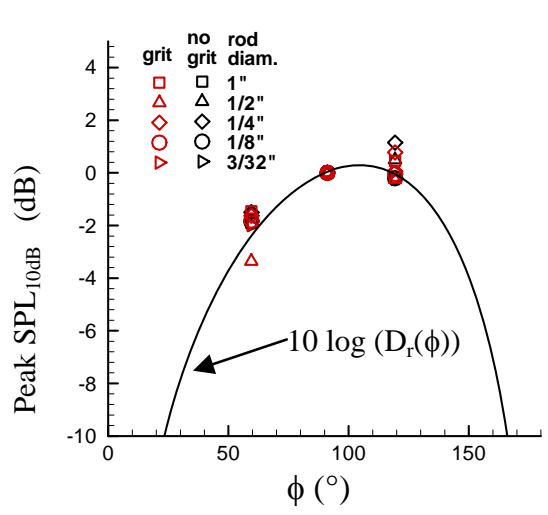

Figure 11. Directivity of vortex shedding tone for single rods; uniform flow; $M=0.13$.

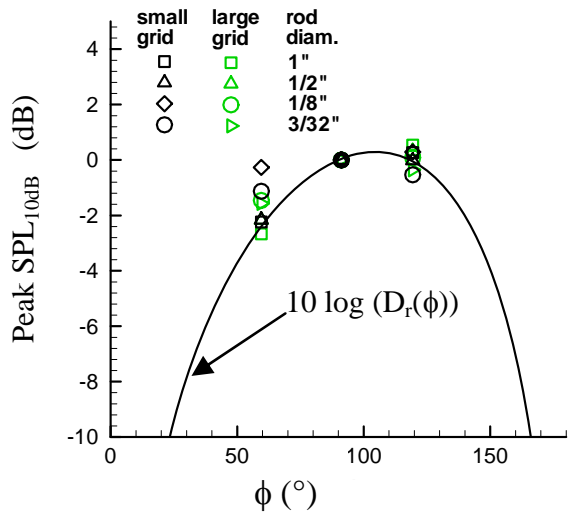

Figure 12. Directivity of vortex shedding tone for smooth single rods. Freestream turbulence, $M=0.13$. 


\section{B. Square bar configurations}

Acoustic measurements were acquired for three different orientations of a square bar with respect to the flow (see Table 1 for a description of this configuration). The bar is 1" 1 1" in cross-section. As for the cylindrical rods, the noise spectra obtained for each orientation of the square bar consist of a large tone at the rods vortex shedding frequency, and two smaller tones (about $25 \mathrm{~dB}$ lower in level than the dominant tone) at twice and three times the vortex shedding frequency. This spectral shape was observed at all speeds.

The variation of peak SPL $10 \mathrm{~dB}$ with respect to Re is displayed in Fig.13. The corresponding data obtained for the cylindrical 1" rod is also shown. Note that for $\alpha=30^{\circ}$, the bar is rotated $30^{\circ}$ towards microphone 38. The peak SPL ${ }_{10 \mathrm{~dB}}$ values in Fig. 13 are scaled with the $6^{\text {th }}$ power of M. It is seen in this figure that peak SPL ${ }_{10 \mathrm{~dB}}$ follows the $6^{\text {th }}$ power velocity dependence. It is also observed that the peak SPL $\mathrm{L}_{10 \mathrm{~dB}}$ values for $\alpha=30^{\circ}$ and $\alpha=45^{\circ}$ are nearly identical to that measured for the smooth $1^{\prime \prime}$ diameter rod. For the $\alpha=0^{\circ}$ case, peak SPL ${ }_{10 \mathrm{~dB}}$ is $6 \mathrm{~dB}$ higher. Unlike for the 1" diameter rod, the application of grit to the surface of the bar did not lead to any significant changes in the peak noise levels.

The variation of St with Re is presented in Fig.14. St was calculated using the bar thickness (1 inch). It is seen that St remained approximately constant over the Re range tested and that the application of grit to the surfaces of the bar did not affect St values. St is approximately equal to 0.12 for the $\alpha=45^{\circ}$ case, 0.125 for the $\alpha=30^{\circ}$ case and 0.13 for the $\alpha=0^{\circ}$ case.

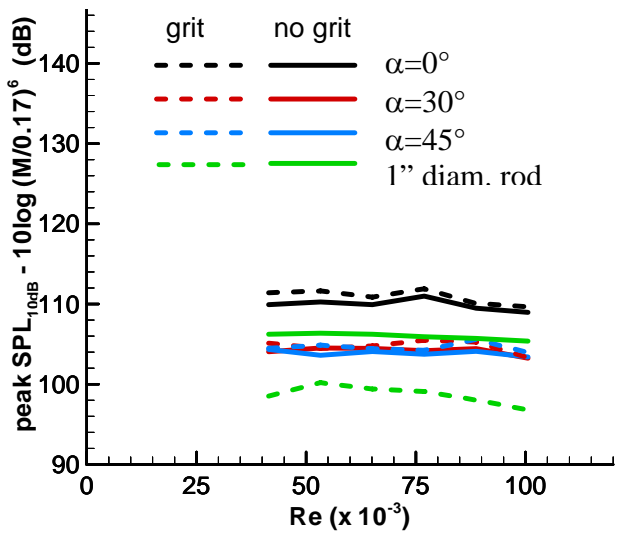

Figure 13. Peak SPL10dB variation with Re; square bar; uniform flow.

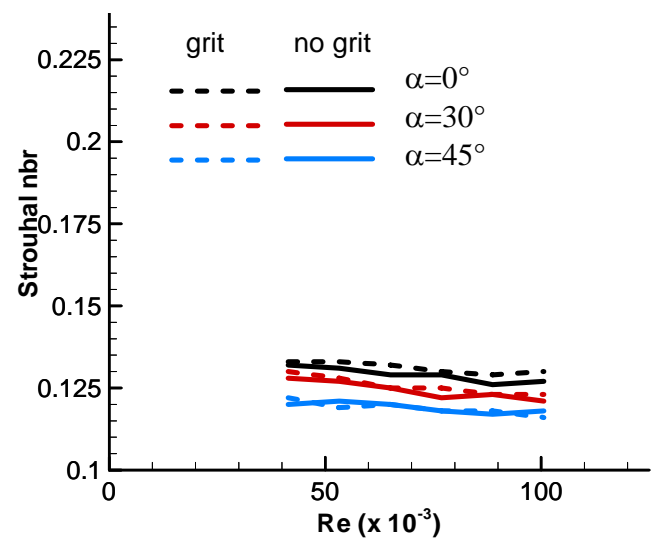

Figure14. St variation with Re; square bar; uniform flow.

The directivity measurements obtained for each bar orientation are shown in Fig. 15, 16, and 17 for $M=0.07$, $\mathrm{M}=0.13$, and $\mathrm{M}=0.17$, respectively. The measurements are plotted against $\mathrm{D}_{\mathrm{r}}(\phi)$. It is seen that the data acquired for $\alpha=0^{\circ}$ collapses best with $D_{r}(\phi)$ (within $1 \mathrm{~dB}$ ), while the data acquired for $\alpha=45^{\circ}$ departs the most from the theoretical directivity pattern. Yet, for $\alpha=45^{\circ}$, the data remains within $3 \mathrm{~dB}$ of the theoretical directivity values.

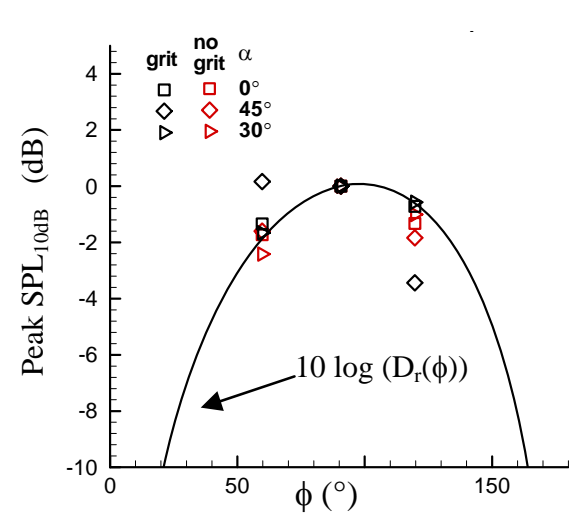

Figure 15. Directivity; square bar; uniform flow; $M=0.07$.

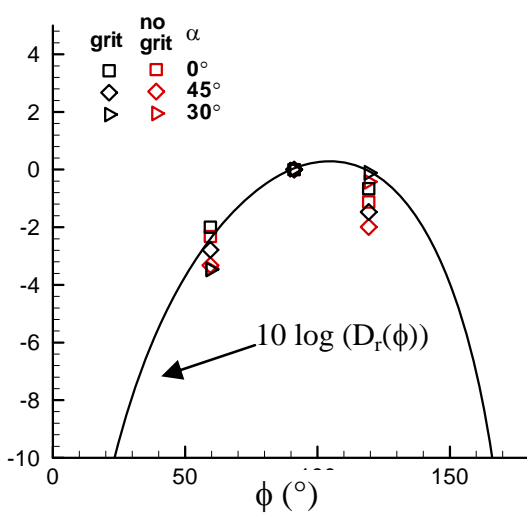

Figure 16. Directıvity; square bar; uniform flow; $M=0.13$.

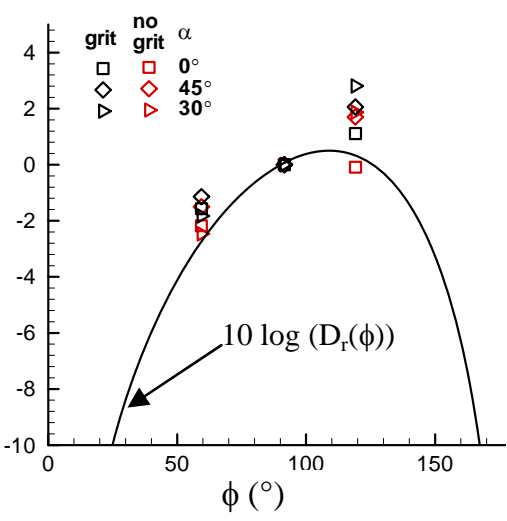

Figure 17. Directivity; square bar; uniform flow; $M=0.17$. 


\section{Rod with side plate configurations}

The noise spectra obtained for the different "rod with plate" model configurations tested are shown in Fig.18. In this figure, the flow Mach number is 0.13 . Spectra obtained at other flow speeds show similar characteristics. It is seen that when there is no gap between the rod and the side plate, the spectra displays a large tone at a frequency that is lower (by $130 \mathrm{~Hz}$, for $\mathrm{M}=0.13$ ) than the vortex shedding frequency of a single 3/4" diameter rod. This large tone is followed by two smaller and broader tones located at frequencies that are slightly higher than twice and three times the frequency of the dominant tone. When there is a gap of 0.1 " between the rod and the plate, the large tone is replaced by one that is 20 to $25 \mathrm{~dB}$ smaller and located at a slightly lower frequency. The peak SPL of this tone was the peak SPL of the spectra only for $\mathrm{M} \geq 0.11$. A very small peak also appears at what would be the vortex shedding frequency of a 3/4" diameter rod.

It is also seen in Fig.18 that when freestream turbulence (generated by grid A) is introduced, the large tone in the no-gap configuration is replaced by a smaller tone at the same frequency and a broad hump (which stretches between $150 \mathrm{~Hz}$ and $700 \mathrm{~Hz}$ for $\mathrm{M}=0.13$ ). When the model is smooth and the Mach number is 0.13 , the peak SPL value of this smaller tone is $17 \mathrm{~dB}$ lower than that with a uniform flow. When the model is gritted, the peak SPL value is $10 \mathrm{~dB}$ lower than with the uniform flow. For the model configuration with a gap, only the hump seen in the no-gap case remains.

The variation of peak SPL ${ }_{10 \mathrm{~dB}}$ with Re is shown in Fig.19. The peak SPL $\mathrm{L}_{10 \mathrm{~dB}}$ values for the gritted rod and plate configuration with a gap are not shown for $\mathrm{Re} \leq 4.8 \times 10^{4}$, since (as previously mentioned) the peak SPL of the tone associated with the fundamental frequency of the vortex shedding was the peak SPL of the spectra only for $\operatorname{Re} \geq 4.8 \times 10^{4}$. It is seen from Fig.19 that the peak $\mathrm{SPL}_{10 \mathrm{~dB}}$ values for the gap and no-gap cases follow the $6^{\text {th }}$ power velocity dependence. It is also seen that the presence of the gap leads to a drastic reduction of the vortex shedding noise over the entire velocity range. Note that the peak SPL ${ }_{10 \mathrm{~dB}}$ values indicated for the freestream turbulence cases were calculated by integrating the SPL over the very broad frequency range of the humps shown in Fig.18 (that is between $150 \mathrm{~Hz}$ and $700 \mathrm{~Hz}$ for $\mathrm{M}=0.13$ ). Integrating SPL over only the "tone like" part of the spectra would have reduced by $3 \mathrm{~dB}$ the peak $\mathrm{SPL}_{10 \mathrm{~dB}}$ value calculated for the no-gap case.

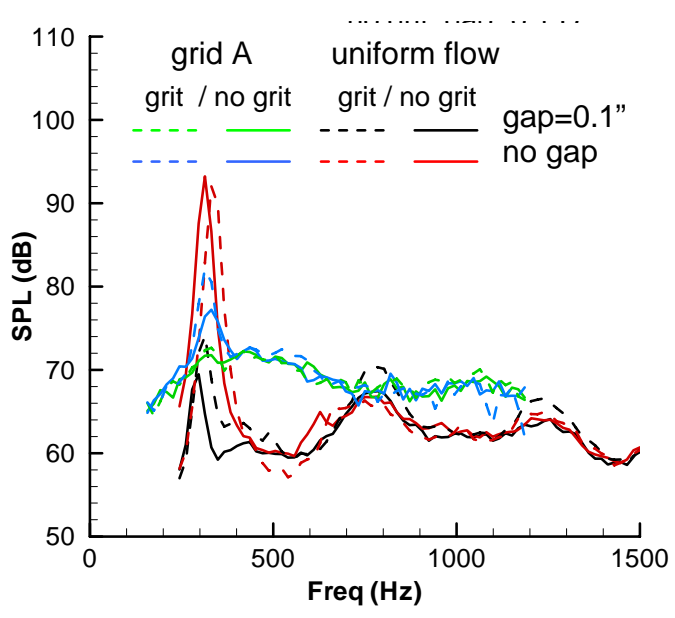

Figure 18. Rod with plate. Noise spectra, $M=0.13$.

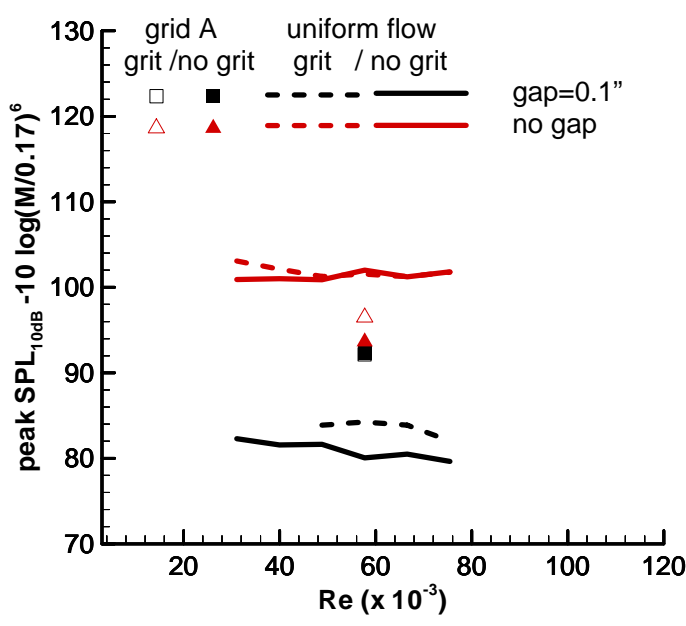

Figure 19. Rod with plate. Variation of peak SPL $_{10 \mathrm{~dB}}$ with Re.

Directivity measurements obtained for the model configurations with and without gap were found to be in very good agreement with $\mathrm{D}_{\mathrm{r}}(\phi)$ at all speeds, in the case of a uniform flow. With freestream turbulence, some directivity data departs from the theoretical directivity pattern by up to $2.5 \mathrm{~dB}$. The directivity results obtained for $\mathrm{M}=0.13$ are shown in Fig.20. The dipole assumption for the directivity of the vortex shedding from a rod with a side plate appears to be valid (at least in the case of an incident uniform flow). 


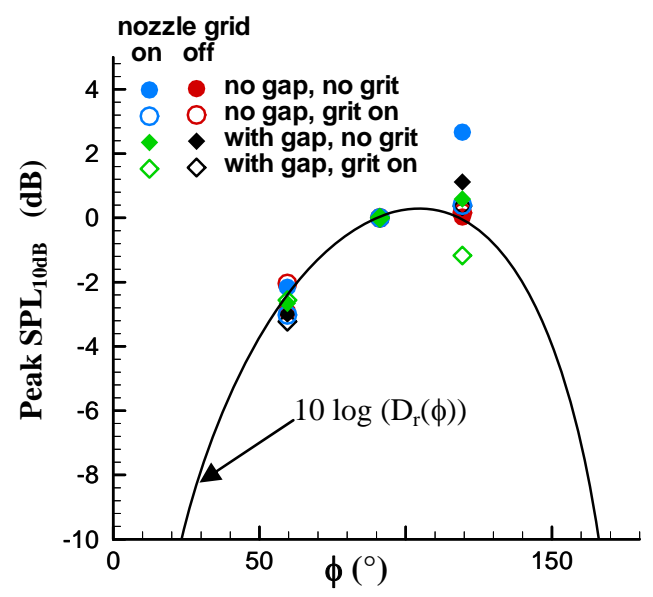

Figure 20. Directivity; Rod with plate; $M=0.13$.

\section{Two rods side by sides}

The acoustic measurements acquired for two 1" rods positioned side by side are presented in this section. The spacing between the two rods is denoted by $S / D$, where $S$ is the distance between the centers of the rods. Noise measurements were obtained for $S / D=1.2, S / D=2$, and $S / D=3$. These particular values of $S / D$ may each lead to three distinct flow regimes. Thus, it has been established in previous studies ${ }^{11}$ that (i) for $1<\mathrm{S} / \mathrm{D}<(1.1-1.2)$, a single vortex street is formed behind both cylinders with a weak gap flow between them; (ii) for (1.1-1.2) $<\mathrm{S} / \mathrm{D}<(2-2.2)$, narrow and wide wakes are formed behind the rods (Here, the gap flow is biased toward the narrow wake and is bi-stable, leading to an interchange of narrow and wide wake behind the rods. This type of flow is also referred to as the biased flow regime); (iii) for $(2-2.2)<\mathrm{S} / \mathrm{D}<(5-6)$, two coupled vortex streets, synchronized in phase and frequency are formed behind the cylinders. (This type of flow is also referred to as the coupled wakes regime). PIV measurements taken in a previous study ${ }^{24}$ indicate the occurrence of the biased flow regime for $\mathrm{S} / \mathrm{D}=2$. PIV measurements were also acquired for $S / D=1$, but not for $S / D=1.2$, nor for $S / D=3$. The vorticity contours obtained from the PIV measurements for $S / D=1$ and 2 are displayed in Fig. 21a and 21b.

The acoustic spectra obtained from microphone 38 for $S / D=1.2$, 2, and 3, and $M=0.13$ are displayed in Fig.22. These results were obtained using smooth rods. The spectra obtained at other flow speeds and for gritted rods have the same characteristics. It is seen in Fig.22 that for $S / D=2$ and 3, the spectra display a large tone at the vortex shedding frequency of a single 1" rod, and also display two small harmonics at twice and three times this vortex shedding frequency. The dominant tone for $S / D=2$ is broader and $10 \mathrm{~dB}$ lower in SPL than for $S / D=3$. This increased broadness of the vortex shedding tone for $S / D=2$ seems consistent with the continuous change between narrow and wide wakes that occurs in the biased flow regime. Thus, the switch between narrow and wide wake is associated with a drift of the vortex shedding frequency between lower and higher values.

For the $S / D=1.2$ case, the spectrum only displays three very small tones of peak SPL 10 to $20 \mathrm{~dB}$ lower than the peak SPL of the dominant tone in the previous cases (note that the background subtraction process causes the sharp drops in SPL level seen in the spectrum, as these small peaks are not far above the background noise level). The first peak is located at a frequency that is approximately one half of the vortex shedding frequency recorded in the two previous cases. The PIV measurements that were acquired for $S / D=1$ (see Fig.21a) reveals the presence of alternate eddies that are spaced as for $S / D=2$, while other larger successive vortices have twice as much spacing between them. It seems reasonable to assume that for $\mathrm{S} / \mathrm{D}=1.2$, a similar vortex shedding pattern occurs, as it is consistent with the presence of multiple spectral peaks (one for each shedding frequency).

The variation of St with Re is presented in Fig.23. Note that St was calculated using D as the reference diameter. It is seen that for $S / D=3$, St varies almost exactly as for the single 1" rod configuration. Thus, for the smooth rods configuration, St remains approximately constant (at a value of 0.19) with increasing Re, while for the gritted rods configuration, an initial jump of St (which occurs when the state of flow transitions from TrSL3 to postcritical) at the lower $\mathrm{M}$ is followed by a decrease of $\mathrm{St}$ to an approximately constant value. When the rods are smooth and spaced 2" apart ( $\mathrm{S} / \mathrm{D}=2)$, St decreases from a value of 0.22 to a value of 0.195 with increasing Re. When the rods are gritted, the initial jump of $S t$ at the lower $M$ is more pronounced than when $S / D=3$. In the postcritical regime, St is of the same value for the side by side $(S / D=2$ and 3$)$ and single rod configurations. Finally, it is 
observed from Fig.23 that the freestream turbulence generated by grid A had no effect on $S t$ for $S / D=2$ (no data were acquired for $\mathrm{S} / \mathrm{D}=3$ or 1.2 )

The variation of peak SPL $\mathrm{L}_{10 \mathrm{~dB}}$ with Re is shown in Fig.24 for the different side by side configurations tested. The peak SPL ${ }_{10 \mathrm{~dB}}$ data obtained for the single 1" diameter rod configuration is added to the plot for comparison. It is seen that peak $S P L_{10 \mathrm{~dB}}$ for a spacing $\mathrm{S} / \mathrm{D}=2$ and $\mathrm{S} / \mathrm{D}=3$ of the smooth rods follows the $6^{\text {th }}$ power velocity dependence best. Peak $S P L_{10 \mathrm{~dB}}$ for $\mathrm{S} / \mathrm{D}=2$ are approximately $5 \mathrm{~dB}$ lower than for $\mathrm{S} / \mathrm{D}=3$. Peak $S P L_{10 \mathrm{~dB}}$ for $\mathrm{S} / \mathrm{D}=1.2$ (smooth rods) are 10 to $20 \mathrm{~dB}$ lower than for the larger spacing cases. It is also noted that for $\mathrm{S} / \mathrm{D}=2$, the freestream turbulence generated by grid A had little effect on peak $\mathrm{SPL}_{10 \mathrm{~dB}}$.

Directivity measurements (shown in Fig.25 for $M=0.13$ ) agree very well with $\mathrm{D}_{\mathrm{r}}(\phi)$. At all speeds, the measured peak SPL are within $1 \mathrm{~dB}$ of the theoretical SPL level. This indicates that the dipole assumption is still valid for the side by side rods configurations when $2 \leq \mathrm{S} / \mathrm{D} \leq 3$.

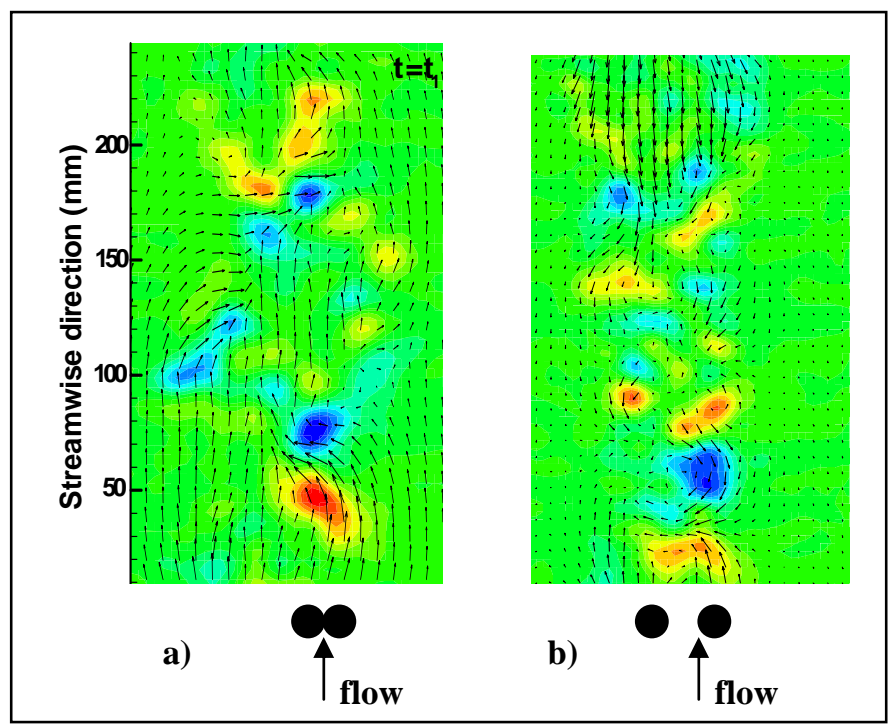

Figure 21. PIV measurements; vorticity contour; $M=0.17$; smooth 1" rods side by side; a) $\mathrm{S} / \mathrm{D}=1$; b) $\mathrm{S} / \mathrm{D}=2$.

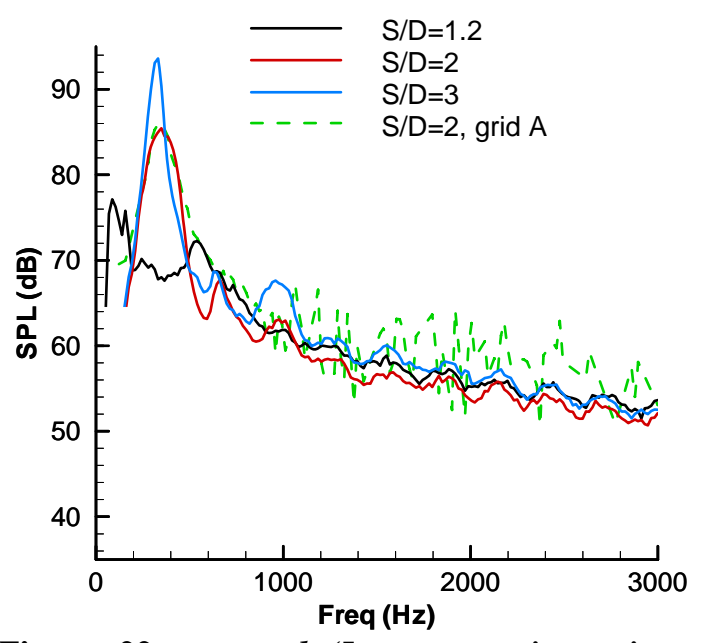

Figure 22 corrected (Incorrect gain setting was accounted for in uncorrected Fig.22). Noise spectra for side by side 1" rods; with uniform flow or with freestream turbulence from nozzle grid A. $\mathbf{M}=\mathbf{0 . 1 3}$.

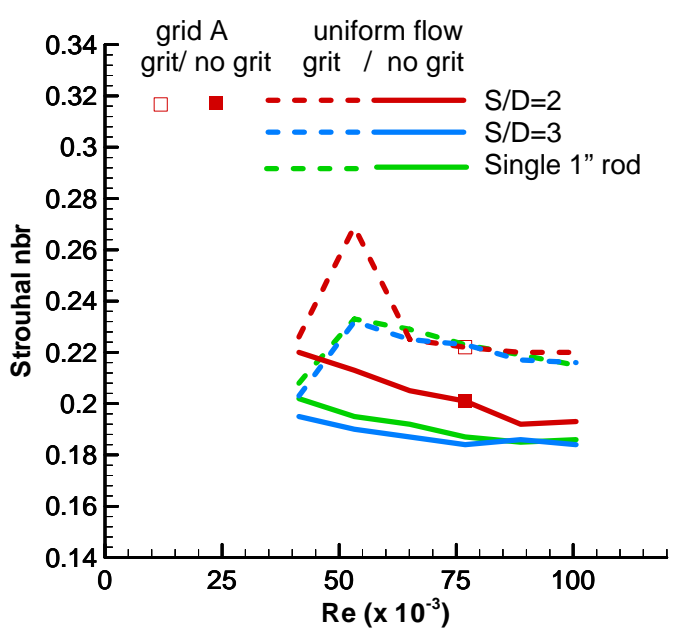

Figure 23. Variation of St with Re; side by side 1" rods. 


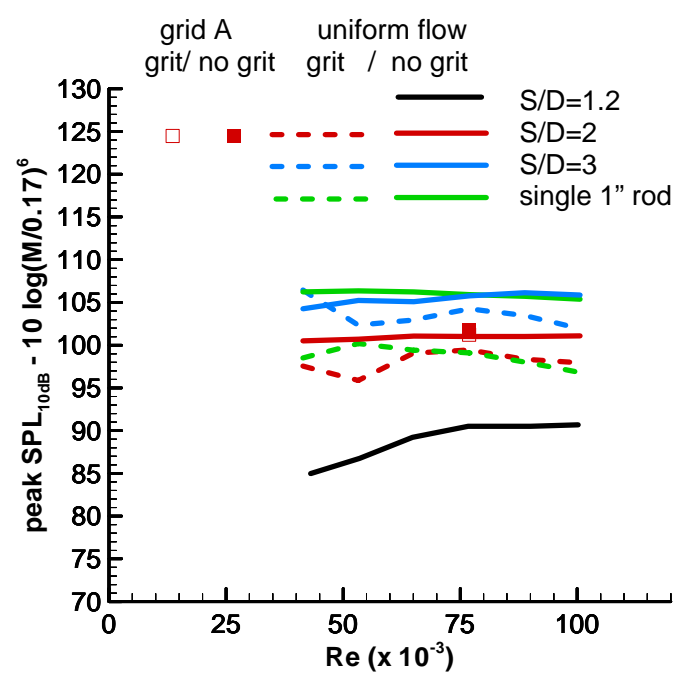

Figure 24 corrected (Incorrect gain setting was accounted for in uncorrected Fig.24). Variation of peak SPL $L_{10 d B}$ with Re. Side by side 1 ” rods.

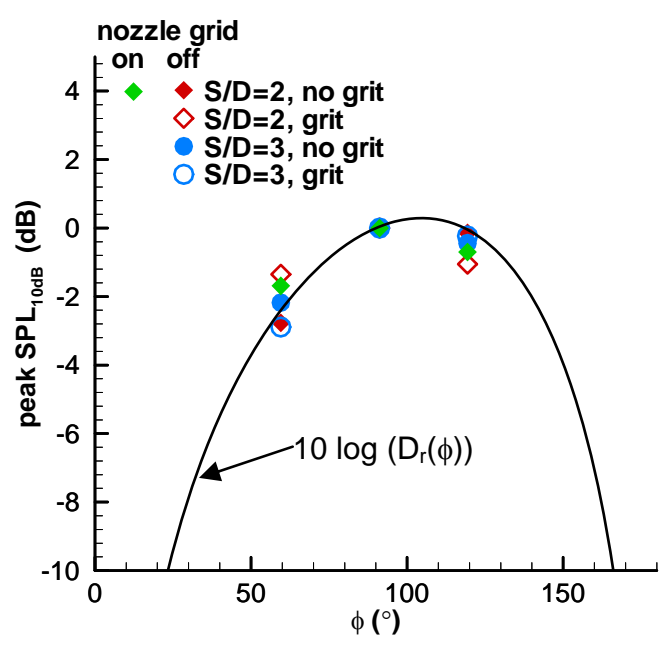

Figure 25. Directivity. Side by side 1" rods; $\mathbf{M}=\mathbf{0 . 1 3}$.

\section{E. Tandem rods of same diameter}

The acoustic measurements acquired from two 1" rods in a tandem arrangement are presented in this section. The spacing between the two rods is denoted by T/D, where $\mathrm{T}$ is the distance between the rods, center to center. Measurements were performed for $T / D=1, T / D=2, T / D=3$, and $T / D=4.5$. These particular values of $T / D$ were chosen as they may each lead to four distinct flow regimes. Zdravkovich has categorized the different possible flow regimes associated with wake interference as follow ${ }^{11}$ : (i) for $1<\mathrm{T} / \mathrm{D}<1.1-1.3$, the free shear layers separated from the upstream rod do not reattach onto the downstream rod. The vortex street behind the downstream rod is formed by the free shear layers separated from the upstream rod; (ii) for $1.1-1.3<\mathrm{T} / \mathrm{D}<3.5-3.8$, the free shear layers separated from the upstream rod may reattach alternately, permanently or intermittently onto the downstream rod. Vortex shedding takes place only behind the downstream rod; (iii) for $3<\mathrm{T} / \mathrm{D}<4$, vortex shedding occurs intermittently behind the upstream rod; (iv) for $3.8<\mathrm{T} / \mathrm{D}<5-6$, the eddies from the upstream rod pair with the eddies behind the downstream rod. The two vortex streets are synchronized in phase and frequency; (v) for T/D $>5-6$, uncoupled vortex shedding takes place behind both rods.

The acoustic spectra obtained from microphone 38 for $\mathrm{M}=0.13$ and $\mathrm{T} / \mathrm{D}=1,2$, 3 , and 4.5 are displayed in Fig.26a for the smooth rods configurations and in Fig.26b for the gritted configurations. The acoustic spectra obtained at other flow speeds have similar characteristics. For $\mathrm{T} / \mathrm{D}=1$, the spectra displays one large tone at a frequency significantly higher than the vortex shedding frequency of a single 1 ” diameter rod. For T/D=2 and $\mathrm{T} / \mathrm{D}=3$, the spectra displays a large tone at a frequency that is lower than that for the single rod configuration. The spectra also contain smaller tones at twice and three times the dominant tone frequency. Finally, for T/D=4.5, the spectra displays one large tone at a frequency that is close to the vortex shedding frequency of a single 1 ” rod.

For $\mathrm{T} / \mathrm{D}=2$ and 3 , the vortex shedding frequency was observed to shift to slightly higher values when the rods are gritted. It was also observed that for the gritted rods and $\mathrm{T} / \mathrm{D}=3$, a second tone (8 to $12 \mathrm{~dB}$ lower than the peak SPL level) appears when $\mathrm{M} \geq 0.11$ (see Fig.26b). This second tone is located at a slightly higher frequency than the dominant tone. For $\mathrm{T} / \mathrm{D}=2$ and $\mathrm{M} \geq 0.11$, the dominant tone broadens as if a second tone is also "trying to breakthrough". No data was taken for the gritted rods configuration with $T / D=4.5$. These shifts of the vortex shedding frequency observed in the spectra for the different tandem configurations are directly reflected in the variation of St.

The variation of St with Re is presented in Fig.27. It is seen that for the smooth rods, St remains approximately constant with increasing Re. The variation of St with increasing T/D is in agreement with findings from Hiwada et

$\mathrm{al}^{28}$. For $\mathrm{T} / \mathrm{D}=1$, the high value of St $(0.3-0.29)$ is consistent with the no-reattachment regime, "(i)", described previously. The flow around the two rods produces a narrow wake which explains the high St value. The low St values (0.13-0.15) for $\mathrm{T} / \mathrm{D}=2$ and $\mathrm{T} / \mathrm{D}=3$, are related to the reattachment regime, “(ii)”. Finally, the rise of St to 0.170.19 is consistent with the coupled eddy street regime, “(iv)”. 


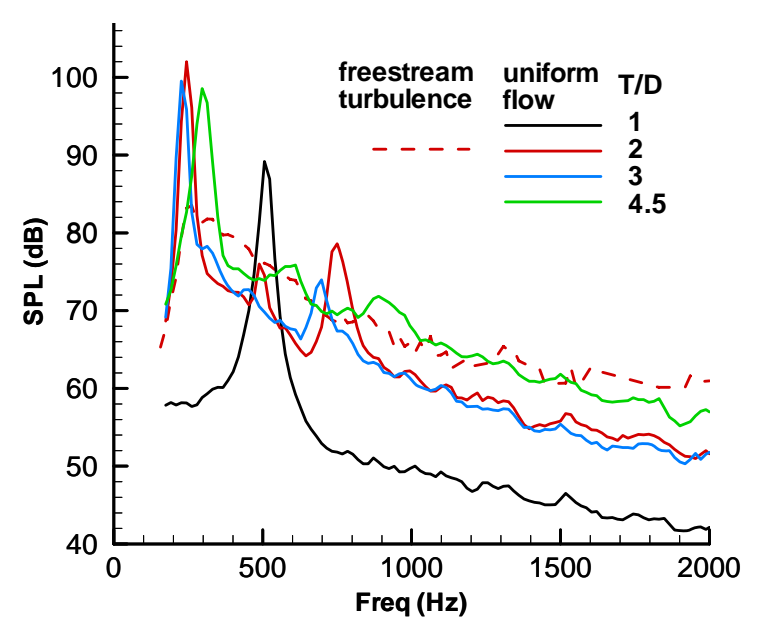

a) smooth rods.

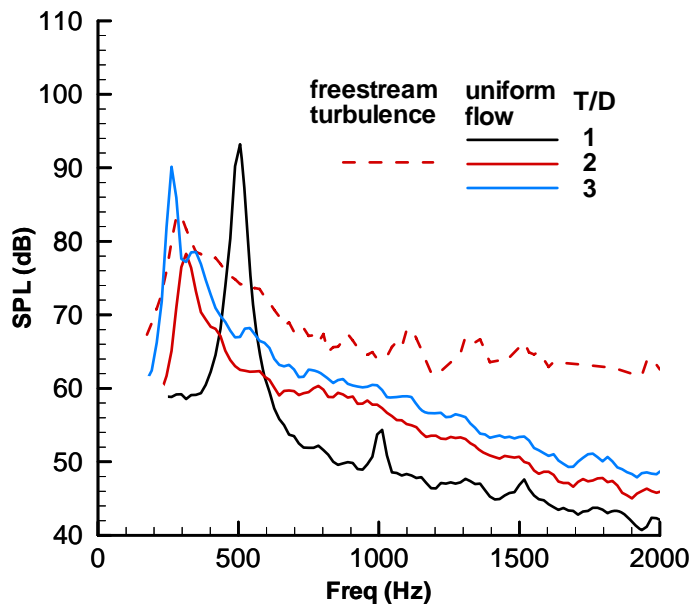

b) gritted rods.

Figure 26. Noise spectra for two 1" rods in tandem. With and without turbulence from grid A. M=0.13.

In a tandem configuration, the rod located downstream is in the wake of the rod located upstream. It is therefore expected that surface roughness and freestream turbulence will have a predominant effect on the flow around the rod located upstream. Okajima ${ }^{29}$ conducted an experiment in which rods were arranged in a tandem configuration with $\mathrm{T} / \mathrm{D}=3$ and 5 ; Re ranged from $4 \times 10^{4}$ to $4 \times 10^{5}$. He observed that when surface roughness is applied only to the upstream rod, the measured values of St were the same as those measured when surface roughness was applied to both rods. It has also been observed ${ }^{11}$ that disturbances to the flow around the upstream rod can lead to early reattachment of the free shear layer in the no-reattachment regime, or can lead also to an early onset of vortex shedding behind the upstream rod in the reattachment regime. The latter would explain the appearance of the second tone in the spectra obtained for $\mathrm{T} / \mathrm{D}=2$ and 3 with the gritted rods when $\mathrm{M} \geq 0.11$. It has also been observed by Bokkaian and Geoola ${ }^{30}$ that for $\mathrm{T} / \mathrm{D}=2$ (with smooth rods), freestream turbulence of intensity $6.5 \%$ (same as in the present test, but the scale of the turbulence was not mentioned) triggered the onset of vortex shedding behind the upstream rod. In their study Re ranged from $1.1 \times 10^{3}$ to $5.6 \times 10^{3}$. The shape of the spectral peak shown in Fig.26b for $\mathrm{T} / \mathrm{D}=2$ with freestream turbulence is indicative of the presence of a second tone at a slightly higher frequency.

The effect of surface roughness on St is seen in Fig.27. For $\mathrm{T} / \mathrm{D}=2$ and 3, St rises (as for the single rod configuration) as the flow around the upstream rod transitions from the precritical to the poscritical regime. Once the poscritical regime is reached, St maintains an approximately constant value. It is noted that for $\mathrm{T} / \mathrm{D}=2$, St rises to a significantly higher value than for $T / D=3$. Thus, for $M \geq 0.11$, $S t \simeq 0.15$ and 0.19 for $T / D=3$ and $T / D=2$, respectively.

It is also seen in Fig.27, that for $T / D=1$, the surface roughness caused an initial drop of $S t$ at $M=0.07$ (note that measurements were only taken at $\mathrm{M}=0.07,0.11,0.13$ and 0.17 for this configuration). For $\mathrm{M} \geq 0.11$, St is close to that for the smooth rods configuration. For this configuration, the usual rise of St associated with the transition from precritical to poscritical state of flow appears to be counteracted by other effects.

The variation of peak SPL ${ }_{10 \mathrm{~dB}}$ with $\mathrm{M}$ is shown in Fig.28, for gritted and smooth rods, and for different spacing between the rods. The peak SPL ${ }_{10 \mathrm{~dB}}$ data obtained for the single 1" diameter rod configuration is added to the plot for comparison. It is seen that peak $S P L_{10 \mathrm{~dB}}$ for $\mathrm{T} / \mathrm{D}=1$ and $\mathrm{T} / \mathrm{D}=4.5$ follows the $6^{\text {th }}$ power velocity dependence as well as for the single rod configuration. For $\mathrm{T} / \mathrm{D}=2$ and for $\mathrm{T} / \mathrm{D}=3$, peak $\mathrm{SPL}_{10 \mathrm{~dB}}$ does not follow the $6^{\text {th }}$ power velocity dependence very well when the rods are smooth. For these configurations, peak SPL ${ }_{10 \mathrm{~dB}}$ slightly rises, then drops with increasing velocities. It is however observed that, once the rods are gritted, the peak $\mathrm{SPL}_{10 \mathrm{~dB}}$ for $\mathrm{T} / \mathrm{D}=2$ and 3 follows the $6^{\text {th }}$ power velocity dependence for $M \geq 0.11$ (i.e., when vortex shedding occurs behind the upstream cylinder).

It is finally noted that with freestream turbulence, for $S / D=2$, the application of grit to the surface of the rods did not change peak $\mathrm{SPL}_{10 \mathrm{~dB}}$ (nor St) significantly. The freestream turbulence (for $\mathrm{Ti}=6.5 \%$ and $\mathrm{T} / \mathrm{D}=2$ ) appears to have more of a governing effect on the state of flow than the surface roughness does.

Directivity measurements are shown in Fig.29 for $\mathrm{M}=0.07,0.13$ and 0.17 . It is seen that they do not agree with the theoretical directivity pattern as well as for the single rods or side by side rods configurations. At the lowest 
speed ( $M=0.07)$ the data for $T / D=1,2$ and 3 departs most from the theoretical directivity pattern. At $M=0.17$, the measured directivity for $T / D=2$ and 3 are in very good agreement with $D_{r}(\phi)$ while for $T / D=1$ and 4.5 , the measurements depart by up to $2.5 \mathrm{~dB}$ from the theoretical directivity pattern. Hence, the dipole assumption for the directivity of the vortex shedding from a tandem rods does not hold as well as for the side by side rods.

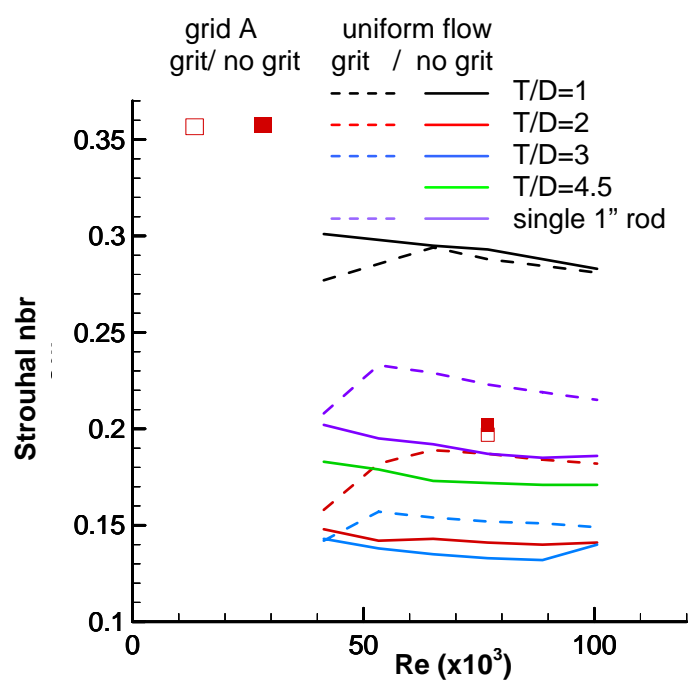

Figure 27. Two 1" rods in tandem. Variation of St with Re.

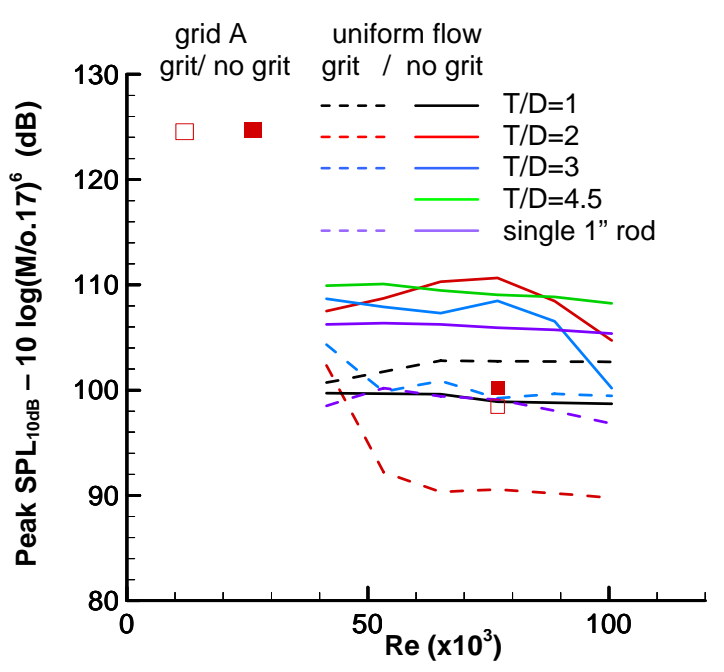

Figure 28. Two 1" rods in tandem. Variation of peak SPL $10 \mathrm{~dB}$ with $R e$.

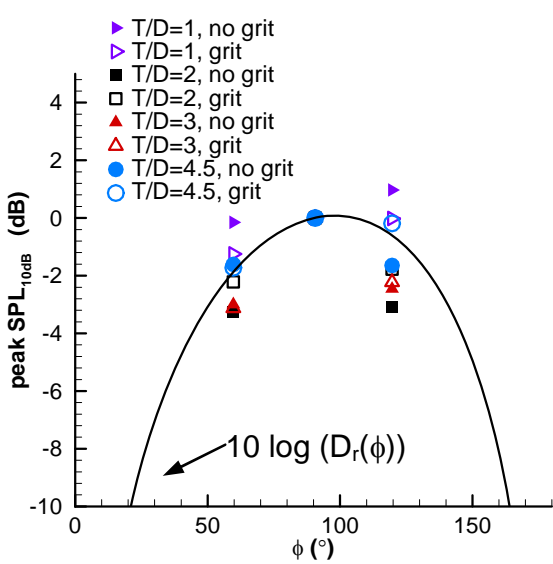

a) $\mathbf{M}=\mathbf{0 . 0 7}$

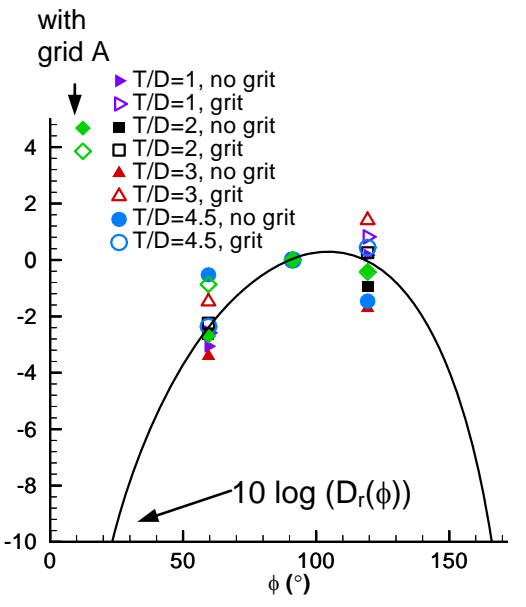

b) $\mathbf{M = 0 . 1 3}$

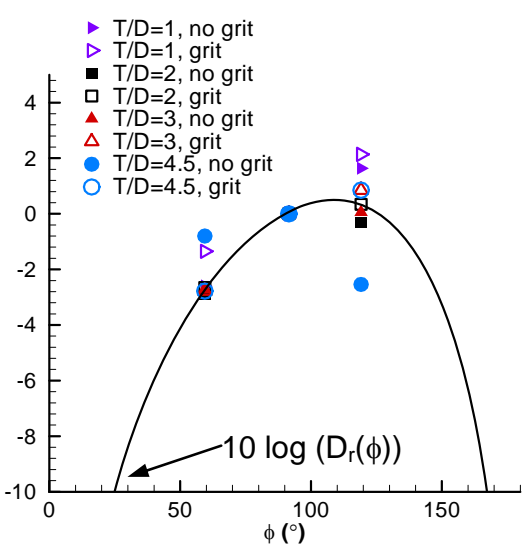

c) $\mathrm{M}=\mathbf{0 . 1 7}$

Figure 29. Directivity. Two 1" rods in tandem.

\section{G. Tandem rods of unequal diameter}

Acoustic measurements acquired for a 1" diameter rod and a 1/2" diameter rod in a tandem configuration are presented in this section. The spacing T between the two rods, center to center, was 3". The 1/2" diameter rod was either placed upstream or downstream of the 1 " diameter rod. In the rest of this analysis, $\mathrm{D}_{1}$ will denote the diameter of the upstream rod while $\mathrm{D}_{2}$ will denote the diameter of the downstream rod.

The acoustic spectra obtained from microphone 38 for $\mathrm{D}_{1} / \mathrm{D}_{2}=0.5\left(1 / 2\right.$ ” rod upstream) and $\mathrm{D}_{1} / \mathrm{D}_{2}=2$ ( 1 ” rod upstream) at $\mathrm{M}=0.13$ are displayed in Fig.30. The spectra are shown for the gritted and smooth rods configurations. 
The spectra obtained for $\mathrm{D}_{1} / \mathrm{D}_{2}=0.5$ with freestream turbulence (from grid $\mathrm{A}$ ) are also shown. The acoustic spectra obtained for these two tandem configurations at other flow speeds have the same characteristics as the ones observed for $M=0.13$. For $D_{1} / D_{2}=2$ and for both smooth and gritted configurations, the spectra displays one large tone at a vortex shedding frequency which is close to that for a single 1" diameter rod. With a smooth rods configuration and for $\mathrm{D}_{1} / \mathrm{D}_{2}=0.5$ (with and without freestream turbulence), the spectra also displays a single large tone, but at a vortex shedding frequency that is close to that for a single 1/2" diameter rod. However, when the rods are gritted, the spectra obtained for $\mathrm{D}_{1} / \mathrm{D}_{2}=0.5$ (again with and without freestream turbulence) exhibit two large tones, one near the vortex shedding frequency of a single 1 ” diameter rod (tone\#1) and the other at twice that frequency (tone\#2). It was observed that for this rod configuration, the peak SPL of tone\#1 was 10dB lower than that for tone\#2 and that the peak SPL of tone\#1 increased with $\mathrm{M}$. For $\mathrm{M}=0.17$, tone\#1 and tone\#2 had a nearly equal peak SPL value.

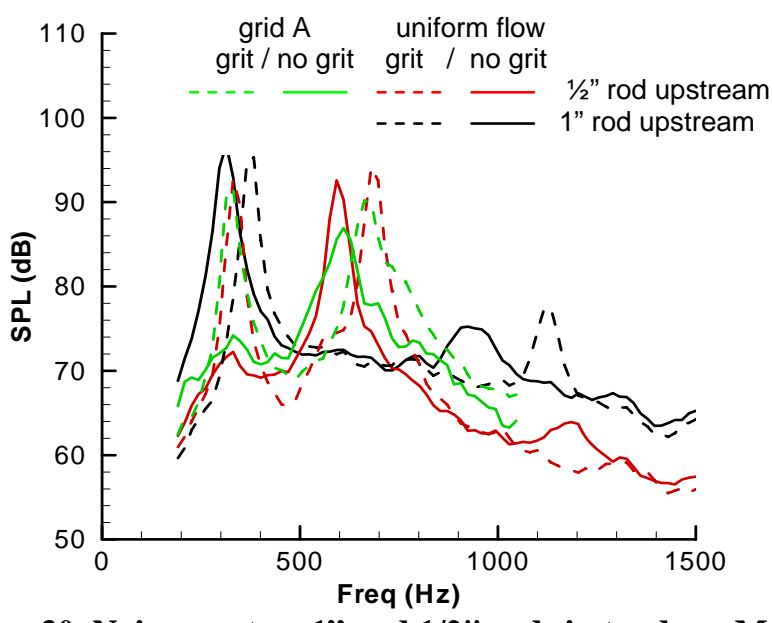

Figure 30. Noise spectra; 1 " and 1/2" rods in tandem; $M=0.13$.

It can be inferred from the above observations, that vortex shedding occurs behind the upstream rod for each of the tandem configuration tested (that is with or without surface roughness and with or without freestream turbulence) and that the vortex shedding from the upstream rod strongly interferes with the vortex shedding from the downstream rod. This interference is expected to be more severe when the larger rod is upstream. This is verified by the presence of a small peak in the noise spectra near the vortex shedding frequency of a single 1 " rod when $\mathrm{D}_{1} / \mathrm{D}_{2}=0.5$, and the absence of such peak near the shedding frequency of a single $1 / 2$ " rod when $D_{1} / \mathrm{D}_{2}=2$. For $\mathrm{D}_{1} / \mathrm{D}_{2}=0.5$, the presence of surface roughness on the two rods leads to an attenuation of the effect that the vortex shedding from the upstream $1 / 2$ " rod has on the vortex shedding of the downstream 1 " rod (thus the appearance of a large spectral peak near the vortex shedding frequency of a single 1" rod). As M increases, the interference of the vortex shedding from the upstream 1/2" rod with the vortex shedding of the downstream 1 " rod weakens. For $\mathrm{D}_{1} / \mathrm{D}_{2}=2$, the vortex shedding from the upstream 1 " rod continued to strongly interfere with the vortex shedding from the downstream 1/2" rod when the rods were gritted (thus the absence of a spectral peak near the vortex shedding frequency of a single 1/2" rod, even at the highest flow speed). From the noise spectra obtained with freestream turbulence, it can also be inferred that for $D_{1} / D_{2}=0.5$, the surface roughness had more influence on the state of the flow than did the freestream turbulence.

The variation of St with Mach number is presented in Fig.31. The values of St obtained from single 1" and 1/2" rods are also shown for comparison. In this figure, St was calculated using 1 ” as the reference diameter, and the frequency of the largest tone in the noise spectra. Hence, the absence of jumps of St between the values of (0.18-0.2) and (0.35-0.4) for a given model configuration (in a uniform freestream flow) indicate that the tone governed by the vortex shedding of the upstream rod remained dominant for the range of Mach number tested. In the case of free stream turbulence, the tone generated by the vortex shedding of the downstream 1" rod was larger than the tone located at the vortex shedding frequency of the upstream 1/2" rod (for the gritted rods configuration).

It is also observed from Fig.31 that St numbers very close in value for both the $D_{1} / D_{2}=2$ configuration and the single 1 " rod configuration. This reinforces the fact that the frequency of the dominant spectral peak for $D_{1} / D_{2}=2$ is dictated by the vortex shedding of the upstream rod. 
The variation of peak SPL $\mathrm{L}_{10 \mathrm{~dB}}$ with $\mathrm{M}$ is shown in Fig.32. Results are shown for gritted and smooth rods, and for $\mathrm{D}_{1} / \mathrm{D}_{2}=0.5$ and 2 . The peak SPL ${ }_{10 \mathrm{~dB}}$ data obtained for single 1 " and $1 / 2$ " diameter rods is added to the plot for comparison. It is seen that the peak SPL $\mathrm{L}_{10 \mathrm{~dB}}$ for $\mathrm{D}_{1} / \mathrm{D}_{2}=0.5$ and 2 follows the $6^{\text {th }}$ power velocity dependence well for $M \geq 0.11$. It is also seen that for the smooth rods configurations, peak $S P L_{10 d B}$ for $D_{1} / D_{2}=2$ is approximately $3 d B$ higher than that for the single 1 " rod configuration, and approximately $6 \mathrm{~dB}$ higher than for $\mathrm{D}_{1} / \mathrm{D}_{2}=0.5$. For the gritted configurations, peak $\mathrm{SPL}_{10 \mathrm{~dB}}$ for $\mathrm{D}_{1} / \mathrm{D}_{2}=2$ remains higher than for $\mathrm{D}_{1} / \mathrm{D}_{2}=0.5$ (except at $\mathrm{M}=0.09$ ).

Finally, directivity measurements of the vortex shedding noise are shown in Fig.33a and 33b, for the smooth and gritted rods configurations, respectively. In these figures, the noise spectra obtained from microphones 37, 38, and 39 are scaled with respect to the theoretical directivity function $\mathrm{D}_{\mathrm{r}}(\phi)$. The results obtained for $\mathrm{M}=0.17$ are shown. It is seen in Fig.33a (smooth rods configurations) that when the 1" rod is upstream the corresponding vortex shedding tone scales with $D_{r}(\phi)$ very well. However, when it is the $1 / 2$ " rod that is upstream, the vortex shedding tone does not scale quiet as well. For the gritted rod configurations, it is seen in Fig.33b that each major tone of the spectra scales very well with $\mathrm{D}_{\mathrm{r}}(\phi)$. The same observations were made at the other flow speeds. Thus, the dipole assumption made for the radiation of the vortex shedding noise from this tandem rods configurations holds very well, except for the smooth rods for $\mathrm{D}_{1} / \mathrm{D}_{2}=0.5$.

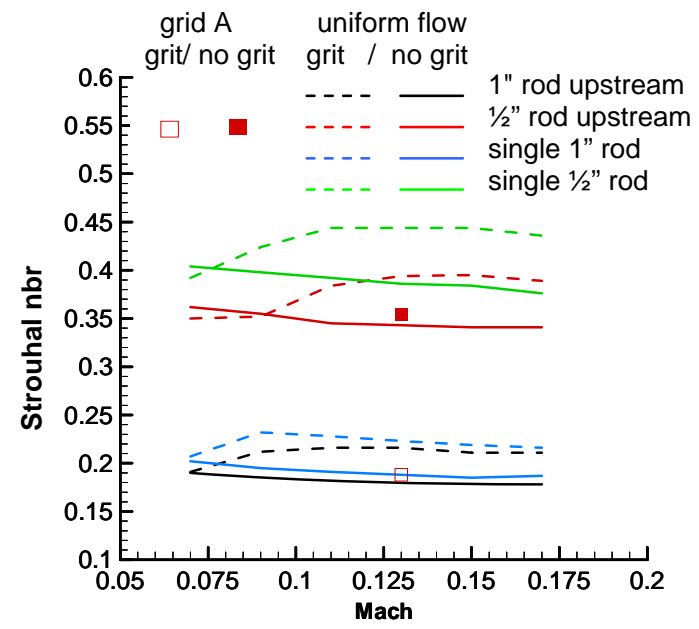

Figure 31. Variation of St with $M ; 1 / 2 "$ and 1" rods in tandem.

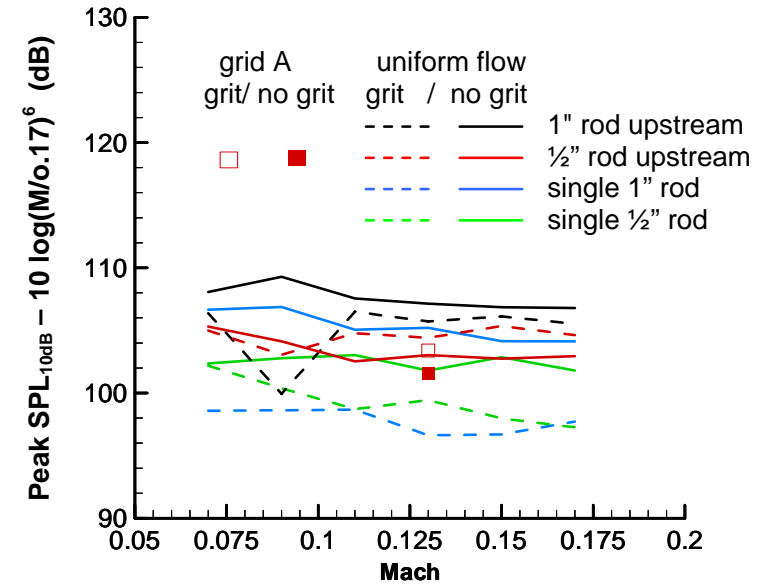

Fig 32. Variation of peak $S P L_{10 d B}$ with $M ; 1 / 2 "$ and 1 " rods in tandem.

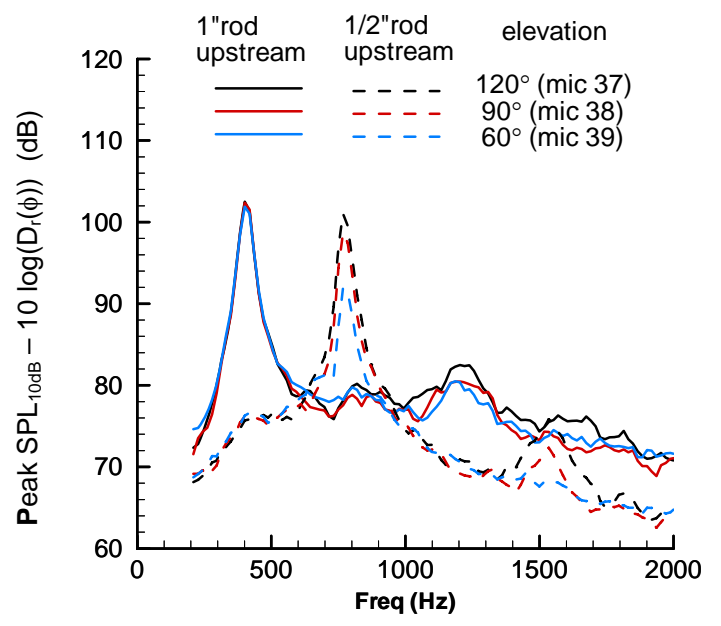

a) smooth rods

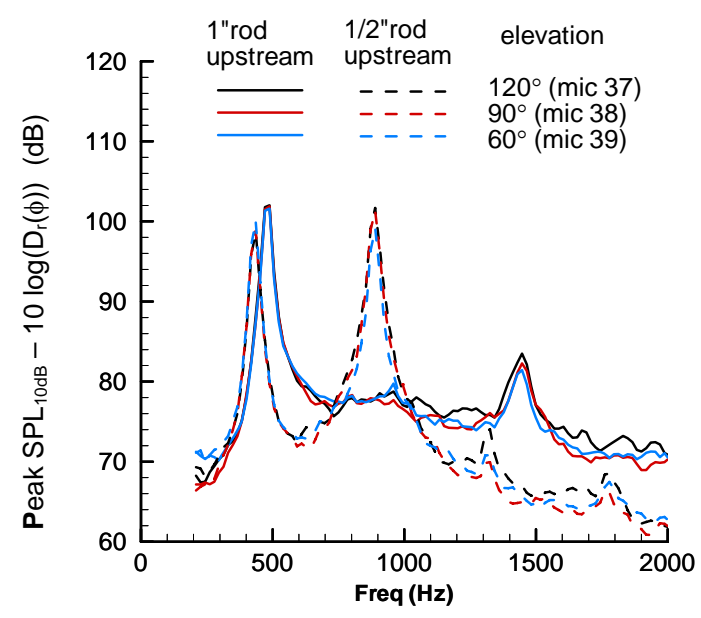

b) gritted rods

Figure 33. Directivity; Noise spectra scaled with $D_{r}(\phi) ; 1 / 2$ " and 1" rods in tandem; $M=0.17$. 


\section{H. Rods with noise reduction devices.}

The effect that collar distributions and wire wraps have on the noise radiated by a cylindrical rod or by rods in tandem configurations is shown in this section.

\section{Single $1 / 2$ " rod with collars or a wire wrap}

The collars used were 1.5" long, 3/4" in diameter and uniformly distributed along the span of a $1 / 2$ " diameter rod. The number of collars distributed along the rod was varied in order to find the configuration that lead to the best reduction of the vortex shedding noise. This optimization process was performed for $M=0.13$ and 0.17 . The spacing between collars, center to center, is denoted by d. It was observed that for both flow Mach numbers, placing two ( $d=12.5$ ") or three ( $d=9.37$ ") collars along the span of the rod did not have any significant effect on the spectral tone associated with the vortex shedding. Placing four collars ( $d=7.5$ ”) reduced the peak SPL by about $4 \mathrm{~dB}$. Placing, successively, 5, 6, and 8 collars along the rod continued to progressively reduce the peak SPL of the tone associated with the vortex shedding. With 10,11, and 12 collars (d=3.41”, 3.12” and 2.88”, respectively), the peak SPL of the vortex shedding tone reaches a minimum and is $30 \mathrm{~dB}$ lower than that for the rod without collars. As the number of collars placed on the rod continues to increase, the vortex shedding tone progressively regains amplitude and drifts toward the vortex shedding frequency of a $3 / 4$ " diameter rod.

The noise spectra measured for a 1/2" diameter rod, a $1 / 2$ " rod with 11 uniformly distributed collars and a 1/2" rod with a 1/8" diameter wire wrapped around it (as described in Table 1) are shown in Fig.34, for $\mathrm{M}=0.17$. The results obtained for smooth and gritted model configurations are shown. It is seen that with the smooth and gritted rod-with-collars configurations, the vortex shedding tone is reduced by $30 \mathrm{~dB}$. With the wire wrap the tone is reduced by $38 \mathrm{~dB}$ and can barely be detected. For the smooth rod-with-wire wrap configuration, the spectra displays a small hump centered near the vortex shedding frequency of a 1/8" diameter rod (diameter of the wire wrapped around the $1 / 2$ " rod). When this rod configuration is gritted, the latter hump disappears.

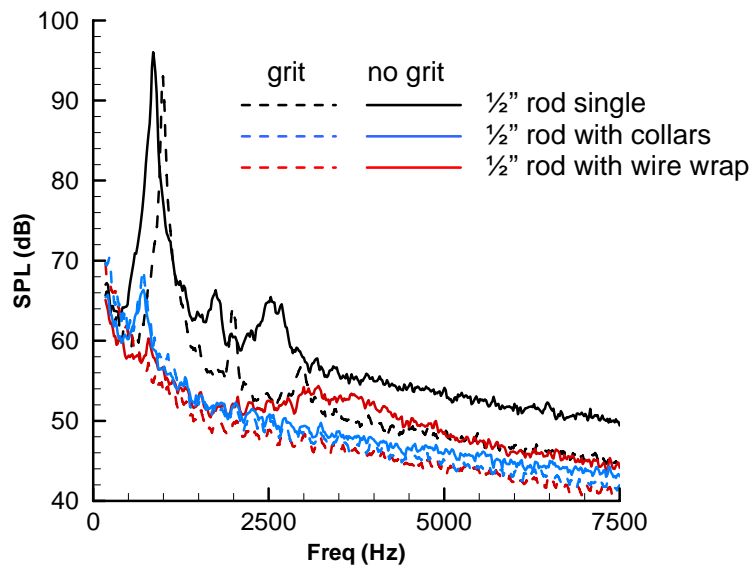

Figure 34. Noise spectra; single 1/2" rod; uniform flow; $M=0.17$.

$1 / 2$ " rod with collars and 1 " rod in tandem ( $T=3$ ")

When the $1 / 2$ " rod is placed downstream of the 1 " rod, the addition of collars to the $1 / 2$ " rod did not change the noise spectra (see Fig.35a). This result indicates that the large tone in the noise spectra for this configuration is strongly governed by the vortex shedding of the upstream 1 " rod.

When the $1 / 2$ " rod is upstream of the 1 " rod, the addition of collars to the $1 / 2$ " rod did affect the noise spectra (see Fig.35b). Thus, for the smooth rods configuration, the large tone that was located at the shedding frequency of the $1 / 2$ " rod (in the absence of collars), is replaced by a tone that is $4 \mathrm{~dB}$ lower in peak SPL and located near the vortex shedding frequency of a 3/4" diameter rod. For the corresponding gritted configuration, the two large tones which (in the absence of collars) were located, respectively, near the shedding frequencies of a $1 / 2$ " and 1" rods are replaced by two smaller tones. One located near the vortex shedding frequency of a 3/4" diameter rod and the other near the vortex shedding frequency of a 1" rod (the latter tone remained significantly lower in SPL than the other one, at all flow speeds). 
The variation of peak $S P L_{10 \mathrm{~dB}}$ with $\mathrm{M}$ is shown in Fig.36 for these tandem configurations. It is seen that over the range of Mach number tested, the collars only lead to noise reduction when placed on the upstream rod. In that case, a reduction of 3 to $6 \mathrm{~dB}$ was achieved for the smooth rods configurations, and a reduction of 4 to $6 \mathrm{~dB}$ was achieved for the gritted rod configurations.

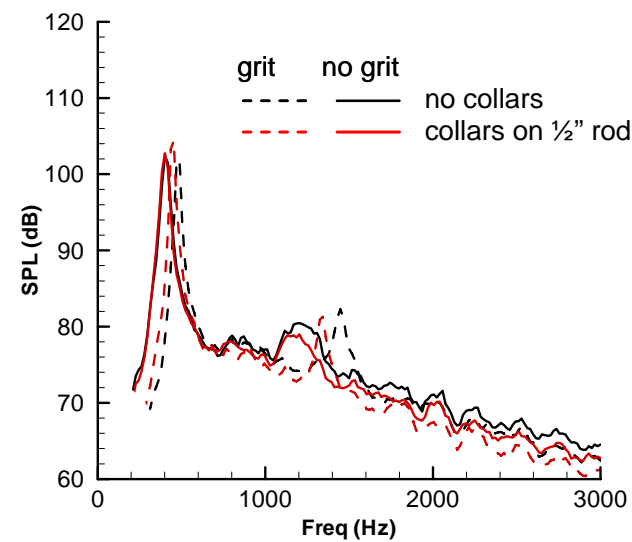

a) 1 " rod upstream

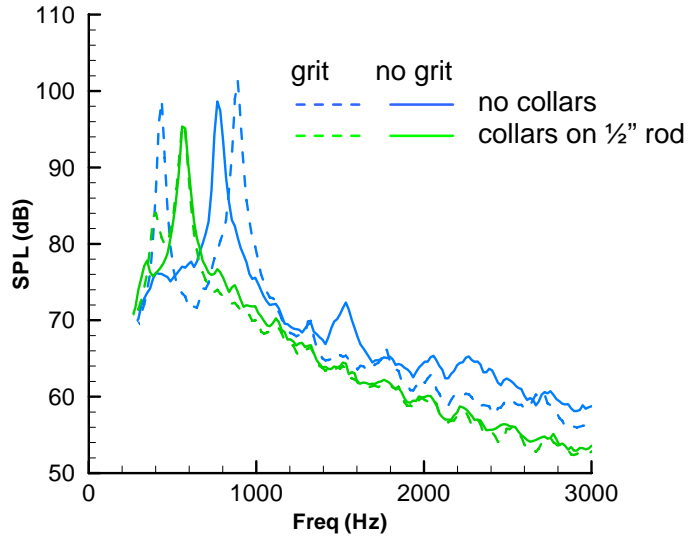

b) $1 / 2 "$ rod upstream.

Figure 35. Noise spectra; 1/2" and 1" rod in tandem, 3" spacing center to center. Collars on 1/2" rod. Uniform flow; $M=0.17$

Tandem 1" rods with wire wrap $(T / D=1)$

In this configuration, a 1/8" diameter wire is wrapped around the two rods (see corresponding sketch in table 1 ). The spacing between loops is 5”. The noise spectra obtained from microphone 38 with and without the wire wrap are displayed in Fig.37. It is seen that the wire wrap leads to a reduction in peak SPL of 23 and 26dB, respectively, for the smooth and gritted configurations.

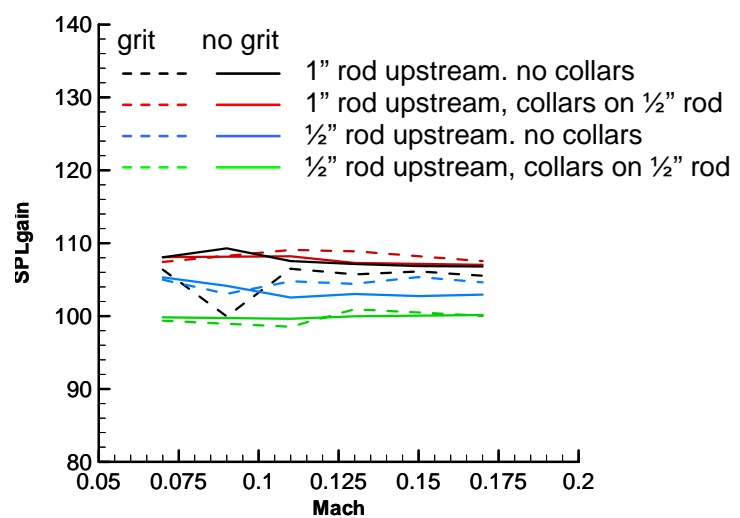

Figure 36. Variation of peak $S P L_{10 \mathrm{~dB}}$ with $M .1 / 2$ " and 1 " rod in tandem, 3 " spacing center to center. Uniform flow.

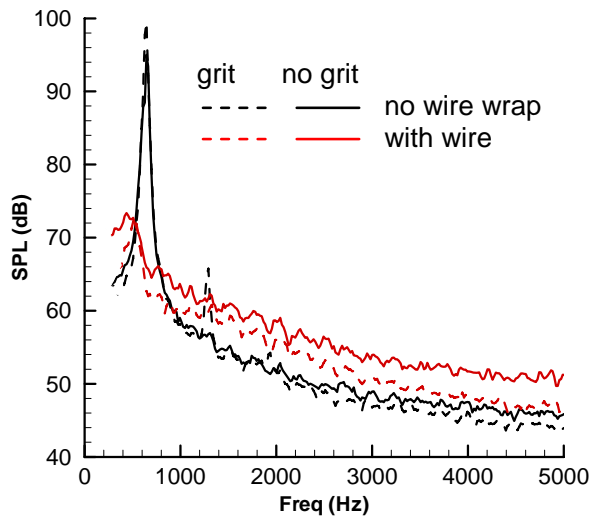

Figure 37. Noise spectra. Tandem 1” rods (no gap). Uniform flow; $M=0.17$ 


\section{Conclusions}

Acoustic measurements were performed on single rod configurations to study the effect of Re, freestream turbulence, and surface grit on the state of the flow around the rod, and on the St and peak SPL values of the vortex shedding noise. It was observed that, for single 1" and 1/2" diameter rods, the application of grit to the surface of the rod caused the flow around the rod to transition from a subcritical regime to the postcritical regime. Freestream

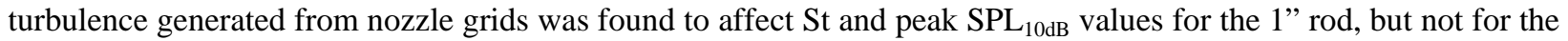
$1 / 2$ " rod. Directivity measurements made for the smooth and gritted rods (with or without freestream turbulence) were found to be in good agreement with the dipole assumption traditionally made for the radiation of the vortex shedding noise.

Measurements of the vortex shedding noise from a square bar were made for different orientations of the bar. In one configuration, two faces of the bar were placed parallel to the flow. For the other two configurations tested, the bar was rotated, respectively, $30^{\circ}$ and $45^{\circ}$ about its axis. For each of these bar orientations, the peak $\mathrm{SPL}_{10 \mathrm{~dB}}$ of the vortex shedding noise was found to follow a $6^{\text {th }}$ power of the velocity dependence while St remained approximately constant with increasing speeds. The St and peak SPL ${ }_{10 \mathrm{~dB}}$ values measured for the smooth bar configurations were nearly identical to those measured for gritted bars. The configuration in which two faces of the bar were parallel to the flow was found to be the noisiest by $6 \mathrm{~dB}$. The directivity of the vortex shedding noise, for the latter configuration, was also found to agree best with the dipole assumption for the radiation.

Measurements performed on a rod-with-side-plate configuration indicated a reduction of the vortex shedding noise when a small gap was introduced between the rod and the plate. When the test model was immersed in a uniform flow, the presence of the small gap between the rod and the plate led to a reduction of 20 to $25 \mathrm{~dB}$ of the peak SPL ${ }_{10 \mathrm{~dB}}$. Peak SPL ${ }_{10 \mathrm{~dB}}$ was also shown to follow the $6^{\text {th }}$ power of the velocity dependence. In the presence of freestream turbulence, the vortex shedding noise of the test model with gap became broadband in nature while that for the no-gap configuration remained more tonal and of higher peak SPL value. Directivity measurements obtained for the model configurations with and without gap indicated that the dipole assumption for the radiation of the vortex shedding noise holds well in the case of a uniform flow. With freestream turbulence, some of the directivity data acquired were found to depart from this theoretical directivity pattern.

Measurements of the noise radiating from two 1" rods positioned side by side were performed for different spacing between the rods. For smooth rods, and for a spacing of the rods that is expected to correspond to the coupled wake flow regime, the peak SPL ${ }_{10 \mathrm{~dB}}$ and St values measured were found to be very close to those measured for a single 1" rod. With a gap of 1 " between the rods (biased gap flow regime), peak SPL $L_{10 \mathrm{~dB}}$ was reduced approximately $5 \mathrm{~dB}$ compare to the previous case. Decreasing the gap between the rods to 0.2 " led to an additional 10-15 dB reduction of peak SPL $10 \mathrm{~dB}$. For the first two model configurations (i.e., for the two largest gaps), peak SPL $_{10 \mathrm{~dB}}$ was found to obey the $6^{\text {th }}$ power of the velocity scaling law and the dipole assumption for the directivity of the noise radiation held.

Measurements of the noise radiating from two 1" rods positioned in tandem were also performed for different spacing between the rods. In the coupled vortex streets regime, peak SPL ${ }_{10 \mathrm{~dB}}$ was found to be higher than that for a single rod of same diameter, while in the no-reattachment regime, peak SPL $\mathrm{L}_{10 \mathrm{~dB}}$ was found to be lower. For both of these flow regimes, peak SPL ${ }_{10 \mathrm{~dB}}$ followed the $6^{\text {th }}$ power velocity dependence. For rods configurations that led to the reattachment regime, peak $S \mathrm{~L}_{10 \mathrm{~dB}}$ did not obey the $6^{\text {th }}$ power velocity scaling law. The radiated noise level for these rod configurations began to followed the $6^{\text {th }}$ power velocity dependence with the onset of vortex shedding behind the upstream rod. The vortex shedding behind the upstream rod was triggered by surface roughness and freestream turbulence. It was also observed that, except in the no-reattachment regime, the presence of surface roughness or freestream turbulence led to a significant reduction of peak $\mathrm{SPL}_{10 \mathrm{~dB}}$. It was finally noted that the dipole assumption for the directivity of the vortex shedding noise from tandem rods did not hold as well as for rods positioned side by side.

Acoustic measurements performed for a 1" diameter rod and a 1/2" diameter rod placed in tandem showed that for the smooth rods configurations, the noise spectra display a single large tone at a frequency dictated by the vortex shedding of the upstream rod. The peak SPL $\mathrm{L}_{10 \mathrm{~dB}}$ of this tone was found to be 3 to $6 \mathrm{~dB}$ lower with the $1 / 2$ " rod upstream of the 1 " rod than with the 1/2" rod downstream of the 1 " rod. It was also observed that with the rods gritted and the 1/2" rod upstream, the 1" rod shed vortices more independently, resulting in the appearance of a second tone in the noise spectra. The dipole assumption made for the radiation of the vortex shedding noise was found to hold very well, except when the rods were smooth with the 1/2" rod upstream.

Finally, the effect that collar distributions and wire wraps have on the noise radiated from rods in tandem configurations was examined. It was shown that distributing collars along the span of a $1 / 2$ " rod that is placed upstream of a 1 " rod led to a reduction of 3 to $12 \mathrm{~dB}$ of the spectral tone(s) associated with vortex shedding. 
Wrapping a wire around two rods in tandem (no gap between the rods) was also found to lead to a $28 \mathrm{~dB}$ reduction of the vortex shedding noise.

\section{References}

1. Smith, M. G., Chow, L. C.: "Validation of a prediction model for aerodynamic noise from aircraft landing gear”, AIAA paper 2002-2581.

2. Souliez, F. J., Long, L. N., Morris, P. J., Sharma, A.: "Landing gear aerodynamic noise prediction using unstructured grids”, AIAA paper 2002-0799.

3. Lockard, D., Khorrami, M.: “Aeroacoustics analysis of a simplified landing gear”, AIAA paper 2003-3111.

4. Guo, Y., Yamamoto, K. Stoker, R.: “An empirical model for landing gear noise prediction”, AIAA paper 20042888.

5. Seror, C., Sagaut, P., Belanger, A.: “A numerical aeroacoustic analysis of a detailed landing gear”, AIAA paper 2004-2884.

6. Ravetta, P., Burdisso, R., Ng, W.: "Wind tunnel aeroacoustic measurements of a 26\%-scale 777 main landing gear”, AIAA paper 2004-2885.

7. Jaeger, Burnside, Soderman, Horne, and James: "Microphone array assessment of an isolated, 26\%-scale, highfidelity landing gear”, AIAA paper 2002-2410.

8. Dobrzynski, W., Buchholz, H.: "Full scale noise testing on airbus landing gears in the German-Dutch Wind Tunnel”, AIAA paper 97-1597.

9. Dobrzynski, W., Chow, L., Guion, P., Shiells, D.: "Research into landing gear airframe noise reduction”, AIAA paper 2002-2409.

10. Zdravkovich, M. M.: “Flow around circular cylinder, Volume 1”, Oxford University Press, 1997.

11. Zdravkovich, M. M.: “Flow around circular cylinder, Volume 2”, Oxford University Press, 2003.

12. Schlinker, R. H., Fink, M. R., Amiet, R. K.: "Vortex noise from nonrotating cylinders and airfoils”, AIAA paper 76-81.

13. Fink, M. R., Schlinker, R. H., Amiet, R. K.: "Prediction of rotating blade vortex noise from noise of nonrotating blades”, NASA CR-2611.

14. Fujita, H., Suzuki, H., Sagawa, A., Takaishi, T.: “The Aeolian tone characteristics of a circular cylinder in high Reynolds number flow”, AIAA paper 99-1849.

15. Olsen, W. A.: "Noise generated by impingement of turbulent flow on airfoils of varied chord, cylinders, and other flow obstructions", AIAA paper 76-504.

16. Davis, M. R., Pan, N. H.: "Noise generated by the interaction of turbulent jets with circular cylinders", Journal of Sound and Vibration (1989), Vol. 135(3), 427-442.

17. Fujita, H., Sha, W., Furutani, H., Suzuki, H.: "Experimental investigations and prediction of aerodynamic sound generated from square cylinders”, AIAA paper 98-2369. 
18. Yoshida, M., Koike, M., Fukano, T.: "A study on Aeolian tones generated from square cylinders with rounded corners", AIAA paper 2003-3218.

19. Mochizuki, O., Kiya, M., Arai, T.: "Aerodynamic sound generated by two parallel circular cylinders in various arrangements”, The Sixth Asian Congress of Fluid Mechanics, May22-26, 1995, Singapore.

20. Fitzpatrick, J. A.: "Flow/Acoustic interactions of two cylinders in a cross-flow", Journal of Fluids and Structures (2003), Vol. 17, 97-113.

21. Ahuja, K. K., Martin, J., Miller, B., Gu, X.: “On automobile antenna and roof rack noise control”, AIAA paper 93-

22. Hutcheson, F. V., Brooks, T. F.: "Measurement of trailing edge noise using directional array and coherent output power methods", AIAA paper 2002-2472.

23. Brooks, T., Pope, D., Marcolini, M.: “Airfoil self-noise and prediction”, NASA reference publication 1218, July 1989.

24. Amiet, R.: “ Refraction of sound by a shear layer”, Journal of Sound and Vibration, Vol.58 (3), 467-482, 1978.

25. Hutcheson, F., Burley, C., Stead, D., Becker, L., Price, J.: “ Landing gear components noise study - PIV and hot-wire measurements”, NASA TM, to be published.

26. Farell, C., Blessmann, J.: “On critical flow around smooth circular cylinders”, Journal of Fluid Mechanics, Vol. 136, 375-391.

27. Achenbach, E., Heinecke, E.: “On vortex shedding from smooth and rough cylinders in range of Reynolds numbers $6 \times 10^{3}$ to $5 \times 10^{6 ”,}$, Journal of Fluid Mechanics, Vol.109, 239-251.

28. Hiwada, M., Mabuchi, I., Yanagihara, H.: "Fluid flow and heat transfer around two circular cylinders”, JSME, Vol. 25, 1737-1745.

29. Okajima, A.: "Flow around two tandem circular cylinders at very high Reynolds numbers”, JSME, Vol. 22, 504-511.

30. Bokaian, A., Geoola, F.: "Vortex shedding from two interfering circular cylinders", ASCE Journal of Engineering Mechanics, Vol. 110, 623-628. 